\title{
Transfer of Cobalt Nanoparticles in a Simplified Food Web: From Algae to Zooplankton to Fish
}

\author{
Nanxuan Mei ${ }^{1}$, Jonas Hedberg ${ }^{1}{ }^{(D}$, Mikael T. Ekvall ${ }^{2,3}$, Egle Kelpsiene ${ }^{3} \mathbb{D}^{D}$, Lars-Anders Hansson ${ }^{2} \mathbb{D}$, \\ Tommy Cedervall ${ }^{3}$, Eva Blomberg 1,4,*(D) and Inger Odnevall 1,5,6,*(D)
}

1 Department of Chemistry, Division Surface and Corrosion Science, School of Engineering Sciences in Chemistry, Biotechnology and Health, KTH Royal Institute of Technology, Drottning Kristinas Väg 51, SE-100 44 Stockholm, Sweden; nanxuan@kth.se (N.M.); jhed@kth.se (J.H.)

2 Aquatic Ecology, Department of Biology, Ecology Building, Lund University, SE-223 62 Lund, Sweden; mikael.ekvall@biol.lu.se (M.T.E.); lars-anders.hansson@biol.lu.se (L.-A.H.)

3 Center for Molecular Protein Science, Department of Biochemistry and Structural Biology, Lund University, P.O. Box 118, SE-221 00 Lund, Sweden; Egle.Kelpsiene@biochemistry.lu.se (E.K.);

Tommy.Cedervall@biochemistry.lu.se (T.C.)

4 Division Bioeconomy and Health, Material and Surface Design, RISE Research Institutes of Sweden, SE-114 86 Stockholm, Sweden

5 AIMES - Center for the Advancement of Integrated Medical and Engineering Sciences at Karolinska Institutet and KTH Royal Institute of Technology, SE-100 44 Stockholm, Sweden

6 Department of Neuroscience, Karolinska Institutet, SE-171 77 Stockholm, Sweden

* Correspondence: blev@kth.se (E.B.); ingero@kth.se (I.O.)

check for updates

Citation: Mei, N.; Hedberg, J.; Ekvall, M.T.; Kelpsiene, E.; Hansson, L.-A.; Cedervall, T.; Blomberg, E.; Odnevall, I. Transfer of Cobalt Nanoparticles in a Simplified Food Web: From Algae to Zooplankton to Fish. Appl. Nano 2021, 2, 184-205. https://doi.org/ 10.3390/applnano2030014

Academic Editor: Angelo

Maria Taglietti

Received: 21 June 2021

Accepted: 20 July 2021

Published: 22 July 2021

Publisher's Note: MDPI stays neutral with regard to jurisdictional claims in published maps and institutional affiliations.

Copyright: (C) 2021 by the authors. Licensee MDPI, Basel, Switzerland. This article is an open access article distributed under the terms and conditions of the Creative Commons Attribution (CC BY) license (https:// creativecommons.org/licenses/by/ $4.0 /)$.

\begin{abstract}
Cobalt (Co) nanoparticles (NPs) may be diffusely dispersed into natural ecosystems from various anthropogenic sources such as traffic settings and eventually end up in aquatic systems. As environmentally dispersed Co NPs may be transferred through an aquatic food web, this study investigated this transfer from algae (Scendesmus sp.) to zooplankton (Daphnia magna) to fish (Crucian carp, Carassius carassius). Effects of interactions between naturally excreted biomolecules from D. magna and Co NPs were investigated from an environmental fate perspective. ATR-FTIR measurements showed the adsorption of both algae constituents and excreted biomolecules onto the Co NPs. Less than $5 \%$ of the Co NPs formed heteroagglomerates with algae, partly an effect of both agglomeration and settling of the Co NPs. The presence of excreted biomolecules in the solution did not affect the extent of heteroagglomeration. Despite the low extent of heteroagglomeration between Co NPs and algae, the Co NPs were transferred to the next trophic level (D. magna). The Co uptake in D. magna was 300 times larger than the control samples (without Co NP), which were not influenced by the addition of excreted biomolecules to the solution. Significant uptake of Co was observed in the intestine of the fish feeding on D. magna containing Co NPs. No bioaccumulation of Co was observed in the fish. Moreover, $10-20 \%$ of the transferred Co NP mass was dissolved after $24 \mathrm{~h}$ in the simulated gut solution of the zooplankton ( $\mathrm{pH} 7$ ), and $50-60 \%$ was dissolved in the simulated gut solution of the fish ( $\mathrm{pH}$ 4). The results elucidate that Co NPs gain different properties upon trophic transfer in the food web. Risk assessments should hence be conducted on transformed and weathered NPs rather than on pristine particles.
\end{abstract}

Keywords: nanoparticles; cobalt; algae; trophic transfer; biouptake; excreted biomolecules

\section{Introduction}

Metallic nanoparticles (NPs) can be dispersed into the environment from different societal applications [1,2], and be generated as a result of combustion and wear [3]. Due to their small size, nano-sized particles pose in many cases a higher risk for environmental exposure compared to larger-sized particles [4] as they may end up in natural food webs. Hence, the assessment of potential environmental hazards requires improved knowledge 
of their environmental fate if dispersed into ecosystems and an understanding of the possibilities for trophic transfer through the aquatic food web $[5,6]$.

Whether the bioaccumulation of metal NPs or their ions/complexes will take place at a lower or a higher trophic level is determined by many factors, including environmental transformations of the NPs, their uptake and the accumulation in prey organisms, as well as their internal fate and localisation in the prey, and the digestive physiology of the predator [7]. The trophic transfer of NPs has as an example been studied in short-time laboratory tests for algae, zooplankton (D. magna) and fish [8]. Zooplankton are commonly used in laboratory tests to investigate whether metallic NPs from surrounding media or food can accumulate in the organism [7]. The ingestion of agglomerated NPs is also possible since zooplankton can filter particles in the size range between 0.1 and $1.5 \mu \mathrm{m}$ [9], and the depuration process is affected by their access to food [10]. Previous findings have shown that the biomagnification of $\mathrm{TiO}_{2} \mathrm{NPs}$ takes place during trophic transfer from algae to zooplankton (D. magna), whereas no subsequent effects were observed on zebrafish feeding on D. magna [11,12]. Settled (sedimented) agglomerates of CuO NPs have been reported to be taken up by worms and then transferred to fish, though no biomagnification was observed in the fish due to the egestion of the NPs and/or their dissolved ionic species [13]. Few studies exist that focus on the transfer of NPs between multiple trophic levels [7].

This study aimed to fill some of these knowledge gaps by providing information on the possibility of Co NPs being transferred in the food web via three trophic levels, from algae (Scendesmus sp.) to zooplankton (D. magna) to fish (Crucian carp). Even though Co is an essential element for many living organisms [14], it can, at high enough concentrations and chemical forms (availability), induce adverse effects on both humans and organisms (e.g., bronchial asthma for humans and lower reproduction for aquatic organisms). The environmental dispersion of Co (including Co NPs) can originate from both natural and man-made sources, e.g., volcano eruptions, the production of wearresistant alloys, pigments and chemicals, sewage effluents, as well as urban and agricultural run-off [14]. Co can also be environmentally dispersed from, e.g., wear debris from WC-Co tire studs (nano-sized Co particles) [15]. Therefore, it is important to understand how and whether Co and Co NPs can be transferred in the food web, bioaccumulate and be toxic towards aquatic organisms.

In this study, algae (Scendesmus sp.) were pre-exposed to Co NPs in water, into which zooplankton (D. magna) were added to filter the algae. The same zooplankton were subsequently supplied as food to the fish (Crucian carp), a widely occurring species in northern Europe, particularly in lakes and creeks. To assess whether Co would bioaccumulate in the organisms, total concentrations of $\mathrm{Co}$ were determined for each organism. For the fish, uptake measurements were performed for several organs. In addition, Co NP dissolution studies were performed in parallel at $\mathrm{pH}$ - and ionic strength conditions relevant for the fish stomach $(\mathrm{pH} 4)$ and the D. magna gut solution $(\mathrm{pH} 7.4)$ to provide an extensive understanding of the fate of transferred Co within the organisms.

The surface affinity $(\alpha)$ between NPs and other particulate matter in solution has been used to predict the trophic transfer of NPs [16]. Correlations have, for example, been shown in D. magna uptake studies with gold $(\mathrm{Au}) \mathrm{NPs}$, though the effect disappeared after a certain depuration period [17]. This study, therefore, investigated the extent of attachment/heteroagglomeration of the Co NPs to algae.

The role of the interaction between natural organic matter (NOM) and NPs on the trophic transfer is another poorly understood aspect. NOM can change the surface properties of metal NPs, which may influence their environmental fate [18]. In this study, the role of organic matter excreted by D. magna (a model for NOM [19]) was investigated to assess its influence on the trophic transfer of the Co NPs in relation to their surface properties, heteroagglomeration with algae, and dissolution. The importance of excreted biomolecules on the toxicity to zooplankton has been reported elsewhere [20]. 
The main objective of this study was hence to elucidate the influence of adsorbed excreted biomolecules, forming an "ecocorona" on Co NPs, on the trophic transfer from algae to zooplankton to fish in a natural food chain. Attenuated total reflection Fourier transform infrared spectroscopy (ATR-FTIR) was employed in situ to probe the adsorption of algae and excreted biomolecules on the Co NPs. The zeta potential (apparent surface charge) was estimated for the Co NPs in tap water, algae solution, and algae solution with excreted biomolecules. Furthermore, total concentrations of Co originating from the heteroagglomerates of Co NPs/algae within the zooplankton and in the organs of the fish and dissolved from the Co NPs in simulated fish stomach and gut solutions were determined by means of graphite furnace atomic absorption spectroscopy (GF-AAS).

\section{Materials and Methods}

\subsection{Particles and Soluble Salt}

Engineered Co NPs (product code CO-M-028M-NP.1000N, LOT \# 1211392979-814, $<100 \mathrm{~nm}$, metal purity-99.9\%) were purchased from American Elements, US. Easily soluble cobalt chloride $\left(\mathrm{CoCl}_{2}\right), 99.9 \%$ trace metals basis, anhydrous beads) was purchased from Sigma Aldrich (Stockholm, Sweden). Detailed particle and surface characterisation are described elsewhere [21]. In short, the dry particles had a size varying between 10 and $50 \mathrm{~nm}$, a BET area of $10.7 \pm 0.2 \mathrm{~m}^{2} / \mathrm{g}$ and a surface oxide composed of both $\mathrm{CoO}$ and $\mathrm{Co}_{3} \mathrm{O}_{4}[21]$.

\subsection{Particle Size and Morphology at Dry Conditions}

A $1 \mathrm{~g} / \mathrm{L}$ Co NP stock solution in 100\% ethanol was sonicated for $15 \mathrm{~min}$. Three drops of the stock solution were applied to 200 mesh TEM copper grids with formvar/carbon support films (Ted Pella, Inc., Redding, CA, USA). The grids were stored at ambient temperature to dry before the measurements. Finally, transmission electron microscopy (TEM) imaging was performed using a Hitachi HT7700 microscope (Hitachi, Japan) operating at $100 \mathrm{kV}$.

\subsection{Solutions}

Particle stock solutions of Co NPs $(10 \mathrm{mg} / \mathrm{L})$ were prepared in deionized water as described in [21].

Tap water (TW) from Lund, Sweden, of well-characterised chemical composition (Table S1), was used throughout this study. Tap water was used in order to have the same water quality as the aquarium water for the Daphnia magna and fish experiments.

Tap water containing algae (TW+algae): A green alga Scendesmus sp. (typical cell size: $12.5 \mu \mathrm{m}$ long, $5 \mu \mathrm{m}$ wide) stock solution was diluted with TW to maintain a relatively constant algae concentration $(450 \mu \mathrm{g} / \mathrm{L})$ throughout the experiment. Algae concentrations (chlorophyll a) were determined for triplicate samples using an AlgaeLabAnalyser instrument (bbe Moldaenke, GmbH, Germany). The total volume was $1 \mathrm{~L}$ for each treatment. One flask per treatment was left for $24 \mathrm{~h}$ with a slightly opened cap. The experimental cultures were kept at a temperature below $18{ }^{\circ} \mathrm{C}$ at an 8:16 light/dark photoperiod.

Excreted biomolecule solution: The excreted biomolecule solution was prepared in one batch prior to the start of the experiment by taking $20 \mathrm{~L}$ of conditioned tap water from two $10 \mathrm{~L}$ aquaria, which initially contained $500 \mathrm{D}$. magna, each feeding on algae. After two weeks, the water was pooled and filtered through a Whatman GF/C filter (GE Healthcare Life Science, Sweden) to remove the zooplankton and any remaining algae. After filtration, a strong anionic exchanger, diethylaminoethyl sepharose (DEAE-sepharose), was added $(25 \mathrm{~mL})$ and left in water for $24 \mathrm{~h}$ under continuous mixing. After this period, the exchanger was filtered out, and the bound material was eluted with $1 \mathrm{M} \mathrm{NaCl}$. After elution from the anionic exchanger, the solution was dialysed for $72 \mathrm{~h}$ against ultrapure water (18.2 $\mathrm{M} \Omega \mathrm{cm}$, Millipore, Solna, Sweden), using a dialysis tube with an MWCO 6000-8000 Da (Spectra/Por ${ }^{\circledR}$ Dialysis membrane, order nr: 132660). After dialysis, the solution was aliquoted and stored at $-20^{\circ} \mathrm{C}$. 
TW with algae and excreted biomolecules: TW solutions with algae and added excreted biomolecules $(0.64 \mathrm{mg} / \mathrm{L}$ TOC) were prepared by removing $2.5 \mathrm{~mL}$ of water from the $1 \mathrm{~L}$ $\mathrm{TW}+$ algae solution $(450 \mu \mathrm{g} / \mathrm{L}$ chlorophyll a) and replacing the same volume with excreted biomolecules. These bottles were left for $24 \mathrm{~h}$ with slightly opened caps. Experimental cultures were kept under $18^{\circ} \mathrm{C}$ at an 8:16 light/dark photoperiod.

Simulated fish gut fluid (SGF): The SGF solution was prepared by mixing $2.0 \mathrm{~g} / \mathrm{L} \mathrm{NaCl}$ (CAS: 7647-14-5, Lot: 17E314108, Assay 100.1\%, VWR Chemicals, Stockholm, Sweden) and $0.0146 \mathrm{~g} / \mathrm{L} \mathrm{HCl}$ (pro analysis hydrochloric acid 25\%, Merck KGaA, Sweden) in ultrapure water $(18.2 \mathrm{M} \Omega \cdot \mathrm{cm}$ resistivity, Millipore, Sweden).

\subsection{Exposure of Co NPs to the Different Trophic Levels, i.e., Algae, Zooplankton and Fish}

Each exposure from algae to zooplankton to fish lasted for three days according to the following procedure:

Day 1: Algae were exposed in TW containing the excreted biomolecule solution both with and without Co NPs (10 mg/L) (prepared as described above).

Day 2: Five-hundred (500) D. magna individuals were added to the algae (Scenedesmus sp.) + excreted biomolecule solutions with and without Co NPs (10 mg/L). All exposure flasks were inverted a few times before adding the zooplankton. The flasks were left for another $24 \mathrm{~h}$ with slightly opened caps.

Day 3-15: The zooplankton were rinsed with tap water each time before feeding the fish (Crucian carp; Carassius carassius - each individual measured and weighed prior to exposure). Rinsing was done on a mesh filter to both remove any particles in the water and/or particles loosely associated with the organisms. Thereafter, sixty (60) D. magna individuals were fed to each aquarium (twenty (20) individuals per fish, i.e., three fish per aquarium (in total 72 fish)). Prior to the feeding, the air bubbling filter system was switched off each time to ensure that no individuals were caught in the filters. This feeding procedure was repeated 8 times during the 15-day exposure, i.e., each exposed fish was fed eight times with exposed D. magna (pre-exposed to algae with and without Co NPs).

These studies included in total 24 aquaria, each containing three crucian carps and eight replicates for each exposure condition.

Day 16: The fish were collected and anaesthetised using benzocaine and were subsequently re-measured and re-weighed before the fish organs (intestine, stomach, muscle, gills and brain) and tissues (blood cells and blood serum) were collected. All samples were stored individually at $-80^{\circ} \mathrm{C}$. Dissection was made of organs from two randomly selected individuals from each aquarium.

The uptake of Co by the exposed zooplankton was determined after day 3 (see above) for eight replicates (each containing twenty (20) D. magna individuals). The organisms were rinsed (see above) and collected before being freeze-dried and stored at $-20^{\circ} \mathrm{C}$ prior to analysis of the total concentration of Co.

The study was performed under permission from the Swedish Board of Agriculture (Dnr M 133-16) according to the current laws in Sweden.

\subsection{Algae and Biomolecule Adsorption Studies}

Attenuated total reflection Fourier transform infrared spectroscopy (ATR-FTIR), using a Bruker tensor 37 FTIR spectrometer with a Platinum ATR-IR accessory, was employed to study the adsorption of algae and excreted biomolecules onto the Co NPs. The ATR-IR accessory consists of a diamond crystal with an angle of incidence of $45^{\circ}$ for the IR beam. An MCT (mercury cadmium telluride) detector with a ZnSe window was used for the in situ adsorption experiments on Co NP films with a working wavenumber range limited to approximately $650 \mathrm{~cm}^{-1}$. In total, 512 scans were collected with a resolution of $4 \mathrm{~cm}^{-1}$ in each experiment. Co NPs (25 mg in $10 \mathrm{~mL}$ ethanol) were dispersed, employing tip sonication for 15 min (Branson Sonifier 250, 50\% pulse mode, output 4). Immediately after sonication, approximately $400 \mu \mathrm{L}$ of the Co NP solution was transferred onto the ATR crystal using a pipette, followed by drying for about $2 \mathrm{~h}$ at ambient air conditions. 
This procedure allowed ethanol evaporation and a layer of NPs to form on the crystal. All spectra were collected every 5 th min up to $2 \mathrm{~h}$ (duplicate exposures) upon exposure to the different water solutions. Background spectra were collected for the Co NP layer in ultrapure water $(18 \mathrm{M} \Omega \mathrm{cm}$, MilliPore, MilliQ, Solna, Sweden). At the end of the experiments, ultrapure water was used to rinse the chamber, i.e., the Co NPs layer, in order to assess whether the adsorption of the biomolecules was irreversible.

Reference spectra of concentrated algae and excreted biomolecule solutions were collected both in air and in ultrapure water. Concentrated algae were prepared by centrifugation of the algae solution $(2000 \times g$ for $1 \mathrm{~min})$. The sedimented algae were collected and transferred to the ATR crystal. To concentrate the excreted biomolecules, the solution was dropped onto the ATR crystal and allowed to dry at ambient air conditions for several hours to allow the tap water to evaporate. Two replicate measurements were performed for each solution. The results showed that the background did not have any influence on the recorded FTIR spectra.

The LOD in terms of adsorption of an equivalent layer of amino acids was estimated to ca. $10 \%$, determined from a signal that can be detected when amino acids were adsorbed to an extent exceeding $10 \%$ of the surface [21].

\subsection{Zeta Potential and Particle Size}

A Zetasizer Nano ZS instrument (Malvern Instruments, U.K.) and the Smoluchowski method were used to estimate the zeta potential from the electrophoretic mobility [22]. Two replicates were investigated for each solution, and each replica was investigated three times.

Measurements of the particle size distribution in solution (10 mg Co NPs/L, pH 10.5) were performed using dynamic light scattering spectroscopy (DLS, Wyatt instruments, USA) by means of photon cross-correlation spectroscopy, PCCS (Nanophox, Sympatec $\mathrm{GmbH}$, Clausthal-Zellerfeld, Germany). The main purpose was to investigate any size differences of the Co NPs in tap water with algae solution with and without the presence of excreted biomolecules. All measurements (triplicate) were made at ambient laboratory temperature $\left(25^{\circ} \mathrm{C}\right)$ and performed after $5 \mathrm{~min}, 1 \mathrm{~h}$ and $24 \mathrm{~h}(1 \mathrm{~mL}$ was pipetted into the PCCS cuvettes and measured for $180 \mathrm{~s}$ ). Prior to the analysis, standard latex particles sized $100 \mathrm{~nm}$ (Malvern instruments) were used as quality controls to ensure the accuracy of the measurements.

\subsection{Dissolution of Co NPs (Metal Release Measurements)}

A Co NPs stock solution was prepared by mixing $12 \mathrm{mg}$ Co NPs (weighted by XP26 DeltaRange Microbalance, Mettler Toledo, Stockholm, Sweden) with $6 \mathrm{~mL}$ ultrapure water, dispersed with sonication and diluted with the different water solutions (see above) to a particle loading of $10 \mathrm{mg} / \mathrm{L}$. The dissolution experiments were performed with a solution volume of $20 \mathrm{~mL}$ in acid-cleaned $60 \mathrm{~mL}$ PMP (polymethylpentene) Nalgene jars, to which the freshly prepared Co NP stock solution was added. Triplicates of the samples with excreted biomolecules (see below), one blank sample (the excreted biomolecule sample without Co NP) and one dose sample were prepared for each set and time of measurements. Dose samples were prepared to determine the actual added amount of $\mathrm{Co}$ (the administered dose) since this dose may differ from the nominal dose as shown for other metal NPs [23]. The dose samples were prepared and acidified $(\mathrm{pH}<2)$ followed by digestion $(200 \mu \mathrm{L}$ sample solution in $3.5 \mathrm{~mL} 65 \%$ ultrapure $\mathrm{HNO}_{3}$ (TraceSELECT Ultra, for trace analysis, $\geq 65 \%$ (T) Lot: BCBL9230V, Fluka), $2 \mathrm{~mL} \mathrm{H}_{2} \mathrm{O}_{2}$ (Suprapur Hydrogen peroxide 30\%, Merck $\mathrm{KGaA}$ ) and $4.3 \mathrm{~mL}$ ultrapure water (in acid-cleaned plastic vials)). The samples were digested for $40 \mathrm{~min}$ in a 705 UV Digester (Metrohm, Germany). The dose samples showed that 50 to $70 \%$ of the nominal dose of Co NPs (due to rapid sedimentation) were actually transferred to the test vessels, resulting in an added Co NP concentration of $6.2 \pm 0.53 \mathrm{mg} / \mathrm{L}$ (nominal dose $10 \mathrm{mg} / \mathrm{L}$ ). Therefore, this administered dose was used for all calculations. 
All exposures of the Co NPs to the different excreted biomolecules and water solutions were performed at room temperature for $5 \mathrm{~min}, 1 \mathrm{~h}$, and 1 day. The following solutions were investigated; (i) algae (450 $\mu \mathrm{g} / \mathrm{L})$ in TW $+10 \mathrm{mg} / \mathrm{L}$ Co NP; (ii) algae $(450 \mu \mathrm{g} / \mathrm{L})+$ excreted biomolecules $(0.64 \mathrm{mg} / \mathrm{L}$ total organic carbon, TOC) in TW $+10 \mathrm{mg} / \mathrm{L} \mathrm{Co} \mathrm{NP}$; and (iii) TW $+10 \mathrm{mg} / \mathrm{L}$ Co NPs. After the exposures, the algae in solution were removed by centrifugation $(1 \mathrm{~min}, 2000 \times \mathrm{g}$ ) (Mini Spin, Eppendorf) and 2-4 $\mathrm{mL}$ of the supernatant was collected and filtered using a $20 \mathrm{~nm}$ membrane $(20 \mathrm{~nm}$ pore size, Anotop filter, Whatman, Sweden) to remove any remaining Co NPs from the solution. The filtered solution was acidified $(\mathrm{pH}<2)$, and the total concentration of released $\mathrm{Co}$ in the solution was measured by means of AAS to calculate the amount of dissolved Co from the NPs after exposure to the different excreted biomolecules. Another $2-4 \mathrm{~mL}$ of the supernatant was directly collected and acidified before measuring the total concentrations and amounts of Co. These amounts equal the total amount of Co NPs and dissolved Co in the solution. Three independent replicas were investigated for each solution.

To study the chemical complexation of Co ions with the excreted biomolecules, the different excreted biomolecule solutions were spiked with 44 and $440 \mu \mathrm{g} / \mathrm{L}$ Co ions (Standard from Perkin Elmer, Sweden). Measurements were performed in TW, TW with algae $(450 \mu \mathrm{g} / \mathrm{L})$, and in algae solution $(450 \mu \mathrm{g} / \mathrm{L})$ mixed with excreted biomolecules $(0.64 \mathrm{mg} / \mathrm{L}$ TOC) and in excreted biomolecule solution $(0.64 \mathrm{mg} / \mathrm{L}$ TOC) without any algae. All samples were centrifuged for $1 \mathrm{~min}$ at $2000 \times g$ to remove the algae from the solution before being acidified and measured by means of AAS.

Individuals of D. magna exposed to Co NP were digested using a 705 UV Digester (Metrohm) to determine possible Co uptake. Approximately $0.0095 \mathrm{~g}$ of the samples were digested for $45 \mathrm{~min}$ in $3.5 \mathrm{~mL} \mathrm{HNO}_{3}$ (TraceSELECT Ultra, for trace analysis, $\geq 65 \%$ (T) Lot: BCBL9230V, Fluka, Göteborg, Sweden), $2 \mathrm{~mL} \mathrm{H}_{2} \mathrm{O}_{2}$ (Suprapur Hydrogen peroxide 30\%, Merck Darmstadt, Germany) and $4.5 \mathrm{~mL}$ ultrapure water.

The digestion of the different fish organs collected from the fish fed with Co NPexposed D. magna was performed using a Milestone ultra CLAVE II microwave digestion system (EMLS, Leutkirch, Germany). Approximately $0.03 \mathrm{~g}$ of each organ was digested for $4 \mathrm{~h}$ at 40 bar at $250{ }^{\circ} \mathrm{C}$ in $4 \mathrm{~mL} \mathrm{HNO}_{3}$ (20\% suprapur, Merck, Darmstadt, Germany). Total concentrations of Co in the D. magna and in the different fish organs were analysed by means of AAS.

\subsection{Chemical Analysis of Released Co in Solutions}

Graphite furnace atomic absorption spectroscopy, GF-AAS (Perkin Elmer, AAnalyst 800 ), was utilised to analyse the amount of released Co in the solution. Standard solutions of known Co ion concentrations $(10,30,60,100 \mu \mathrm{g} / \mathrm{L})$ were prepared in $1 \%$ ultrapure $\mathrm{HNO}_{3}$ together with a blank sample $\left(1 \%\right.$ ultrapure $\left.\mathrm{HNO}_{3}\right) . \mathrm{Mg}\left(\mathrm{NO}_{3}\right)_{2}$ was used as a matrix modifier. The limit of detection, $\mathrm{LOD}$, was approximately $3.6 \mu \mathrm{g} / \mathrm{L}$ (the mean value of blank samples + three times the standard deviation of the blank samples). A calibration standard was used for quality control and ran every $4^{\text {th }}$ sample to ensure that there were no memory effects. Calibration and analysis were repeated if the quality control sample deviated by more than $10 \%$.

\subsection{Heteroagglomeration between Au NPs and Algae}

To verify the heteroagglomeration experiments between Co NPs and algae, similar studies were performed with Au NPs. These studies were performed using a Varian Cary 300 Bio UV-VIS-spectrometer (short UV-Vis, Varian, Sweden) using a scan rate of $600 \mathrm{~nm} / \mathrm{min}$, a data interval of $1 \mathrm{~nm}$, an UV-Vis SBW $2 \mathrm{~nm}$, an UV-Vis energy of 1.00 and a single front beam mode. The measurements were performed in a $10 \mathrm{~mm}$ quartz rectangular stoppered cell, a Teflon stopper (Varian, Sweden). Au NPs were purchased from Aldrich (741981-25ML, Lot\# MKCG8167, $40 \mathrm{~nm}$ diameter, OD 1, stabilised suspension in a citrated buffer, MW $196.97 \mathrm{~g} / \mathrm{mol})$. The Au NPs were dispersed $(0.39,1.95,3.9$ and $7.8 \mathrm{mg} / \mathrm{L})$ in ultrapure water as standard solutions for the UV-Vis measurements. Ultrapure water was 
also used for the blank samples and as the baseline for the measurements. Measurements were performed on Au NPs (3.9 mg/L) dispersed in algae + TW solutions during the same time periods as for the Co NP exposures, i.e., $5 \mathrm{~min}, 1 \mathrm{~h}$ and 1 day. After the exposure, the algae in solution were ultrasonically separated from the solution $(1 \mathrm{~min}, 2000 \times g)$, and the supernatant was collected and analysed using UV-Vis (three replicas). The results are presented as average numbers.

\subsection{Statistical Analysis}

Student's $t$-test analysis was performed in double-side mode to compare the difference between the results of several groups of metal release samples.

\section{Results and Discussion}

\subsection{Characteristics of the Co Nanoparticles (NPs)}

Based on the TEM imaging of the unexposed Co NPs under dry conditions (Figure 1), the Co NPs revealed a polyhedral morphology with a primary size typically between 10 and $50 \mathrm{~nm}$. Previous studies of the authors report a BET surface area of $10.7 \pm 0.2 \mathrm{~m}^{2} / \mathrm{g}$. The NPs consisted of a core of Co metal covered by a surface oxide predominantly composed of crystalline $\mathrm{CoO}$ and amorphous $\mathrm{Co}_{3} \mathrm{O}_{4}$ (based on XPS and XRD findings) [21]. Previous findings in, e.g., deionised water and synthetic freshwater, show that the Co NPs, due to strong van der Waals forces, readily agglomerate in solution, forming larger sized aggregates [23].

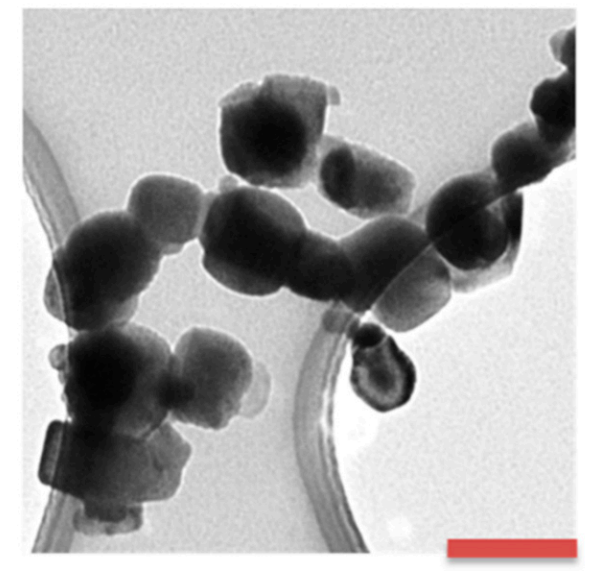

Figure 1. TEM image of unexposed Co NPs. The scale bar equals $50 \mathrm{~nm}$.

\subsection{Trophic Level 1: Algae}

3.2.1. Interactions between Co NPs and Aqueous Colloids (Algae and Excreted Biomolecules)

Studies on the first trophic level in this study involved the interaction between Co NPs and (i) algae (Scenedesmus sp.); (ii) excreted biomolecules and algae; and (iii) excreted biomolecules in TW. Surface interactions between the Co NPs and the excreted biomolecules were studied to understand changes in the surface properties of the Co NPs and their heteroagglomeration behaviour. Both processes have implications for the potential transfer of Co NPs to the next trophic levels (D. magna and Crucian carp).

The main component of the phytoplankton algal cell wall is cellulose, which also contains glycoproteins and polysaccharides that may promote interactions with the NPs [24] During stress (e.g., in the presence of NPs), the algae can secrete high-molecular polymers, extracellular polymeric substances (EPS), which form a protective layer outside the algal cell. The EPS is mainly $(70-80 \%)$ composed of proteins and polysaccharides [25]. 
D. magna will, upon digestion of the algae, mainly extrude degraded algae constituents (e.g., proteins and polysaccharides), i.e., the excreted biomolecules investigated in this study [20].

ATR-FTIR was used to study the adsorption of these different excreted biomolecules onto a film of Co NPs deposited onto the ATR crystal (see Materials and Methods). Spectra generated in TW, in TW with algae, in TW with excreted biomolecules, and in TW containing both algae and excreted biomolecules are presented in Figure 2. Since the concentration of algae and excreted biomolecules investigated in the adsorption studies did not, due to low concentrations, give any detectable spectral features from species in the bulk solution, results of highly concentrated excreted biomolecule and algae solutions are included for comparison in Figure 2B,C. The $\mathrm{pH}$ was adjusted to 10.5 in all solutions to mimic the experimental conditions in the trophic transfer experiments with $D$. magna fed on algae in solutions containing Co NPs.
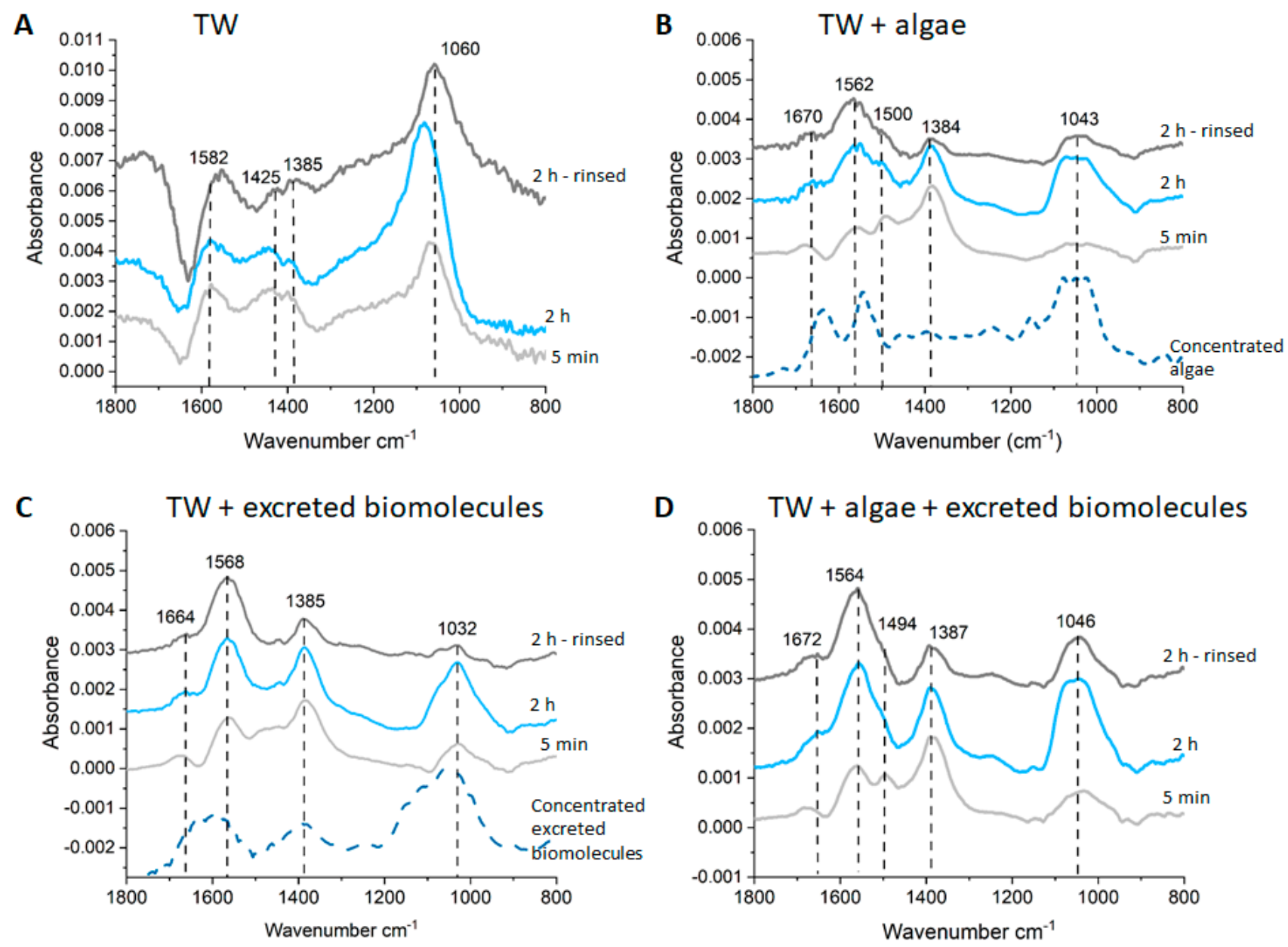

Figure 2. ATR-FTIR spectra in tap water (TW) with and without algae and excreted biomolecules at pH 10.5: (A) Co NPs in TW; (B) Co NPs in TW containing algae; (C) Co NPs in TW with excreted biomolecules; and (D) Co NPs in TW containing both excreted biomolecules $(0.64 \mathrm{mg} / \mathrm{L} \mathrm{TOC})$ and algae (450 $\mathrm{\mu g} / \mathrm{L}$ chlorophyll a). The dashed line in B displays a concentrated algae solution without Co NPs, and in C, the dashed line corresponds to a concentrated excreted biomolecule (>192 mg/L TOC) solution. Co NPs in pure water was used as the background spectra for all experiments. The spectra are offset for clarity, and the absorbance was reduced for the concentrated solutions to fit the numbers of the Co NPs adsorption spectra. 
For the Co NPs in TW (Figure 2A), the main observed vibrational bands were assigned to adsorbed carbonates as a result of the alkalinity $\left(50 \mathrm{mg} / \mathrm{L} \mathrm{HCO}_{3}{ }^{-}\right.$) of the TW (Table S1). At the $\mathrm{pH}$ investigated in this study (10.5), the equilibrium of the carbonate system in TW shifts to a higher concentration of $\mathrm{CO}_{3}{ }^{2-}$ relative to the $\mathrm{HCO}_{3}{ }^{-}$concentration [26]. The vibrational bands shown in Figure $2 \mathrm{~A}$ are attributed to symmetric $\mathrm{CO}_{3}{ }^{2-}$ at $1060 \mathrm{~cm}^{-1}$ and asymmetric $\mathrm{CO}_{3}{ }^{2-}$ at 1385, 1425 and $1582 \mathrm{~cm}^{-1}$ (Table 1) [26]. When the $\mathrm{CO}_{3}{ }^{2-}$ ion coordinates with a surface (monodentate and bidentate coordination), the asymmetric band (at $1383 \mathrm{~cm}^{-1}$ in solution) splits due to a change in symmetry of the molecule (Table 1) [27]. The splitting of the asymmetric vibration bands in Figure 2A shows possibilities of both monodentate and bidentate coordination between $\mathrm{CO}_{3}{ }^{2-}$ and the Co NP surface. After rinsing the Co NP film with pure water, the vibrational bands originating from carbonate were still present, indicating an irreversible bonding.

Figure 2B,C clearly shows that the spectral features in algae and excreted biomolecule bulk solutions (dashed lines) show relatively similar vibrational bands, summarized in Table 1. This was expected since the excreted biomolecules originate from degraded algae conditioned/depurated by D. magna in TW. The strongest vibrational features in the $1500-1680 \mathrm{~cm}^{-1}$ region were mainly assigned to amide I and II bands originating from proteins or polypeptides. These features are more separated and visible in the algae solution compared with the excreted biomolecule solution. However, the vibrational band for amide II at around $1570-1580 \mathrm{~cm}^{-1}$, may also include contributions from asymmetric stretching carboxylate vibrations and amino acid side chains $[19,28]$. The presence of the band at $1385 \mathrm{~cm}^{-1}$ (symmetric stretching of carboxylate) clearly shows the presence of carboxylic-containing molecules in the solutions, especially in the excreted biomolecule solution. The prominent band with peaks at ca. $1000-1100 \mathrm{~cm}^{-1}$ can be assigned to C$\mathrm{O}-\mathrm{C}$ vibrations from polysaccharides [29], or different types of $\mathrm{C}-\mathrm{OH}, \mathrm{C}-\mathrm{C}$, and $\mathrm{C}-\mathrm{O}$ vibrations from the biomolecules [30]. Observed findings are in line with the presence of biomolecules excreted by D. magna [31], and natural organic matter in general regarding carboxylate-containing species [32].

The findings show that the exposure of the Co NP films to solutions containing algae, excreted biomolecules, and algae + excreted biomolecules in all cases resulted in biomolecule adsorption, i.e., the formation of an ecocorona (Figure 2B,D). This is evident from the vibrational bands originating from the biomolecules in these solutions, with some peak shifts and different relative intensities compared with the pure solutions, see Table 1 (Figure 2B,D). The peak shift indicates some structural changes of the adsorbed molecules and/or interactions between the metal NPs and the functional groups of the biomolecules $[28,33]$. Carbonate from TW may also be adsorbed onto the Co NPs, with the most notable contribution being the band at approximately $1060 \mathrm{~cm}^{-1}$.

Directly after exposure (after $5 \mathrm{~min}$ ), the strongest bands for Co NPs exposed in TW containing algae were observed at 1385, 1505, 1584 and $1685 \mathrm{~cm}^{-1}$. The relatively strong band at $1385 \mathrm{~cm}^{-1}$ indicates the adsorption of carboxylate-containing molecules in addition to proteins and polypeptides. The weaker band at $\approx 1043 \mathrm{~cm}^{-1}$ implies the minor adsorption of carbonates or polysaccharide-type species at the beginning of the exposure (5 $\mathrm{min}$ ). In the excreted biomolecule solution, the main vibrational bands were, already after $5 \mathrm{~min}$, relatively similar to bands observed in the algae solution even though the absorbance band at $\approx 1032 \mathrm{~cm}^{-1}$ was slightly stronger and the band at $1584 \mathrm{~cm}^{-1}$ shifted to lower frequencies. Exposures in TW with both algae and excreted biomolecules (Figure 2D) resulted in similar spectra, as observed in TW with both algae and in TW with excreted biomolecules (Figure 2B,C) 
Table 1. Observed peak positions (in $\mathrm{cm}^{-1}$ ) and their assignments in the region between 800 and $1800 \mathrm{~cm}^{-1}$ in ATR-FTIR spectra for Co NP films exposed to TW; TW and algae; and TW containing excreted biomolecules.

\begin{tabular}{|c|c|c|c|c|c|c|}
\hline Algae Only & $\begin{array}{c}\text { Excreted } \\
\text { Biomolecules } \\
\text { Only }\end{array}$ & $\begin{array}{l}\text { Co NPs in } \\
\text { TW }\end{array}$ & $\begin{array}{l}\text { Co NPs in TW } \\
+ \text { Algae }\end{array}$ & $\begin{array}{l}\text { Co NPs in TW } \\
+ \text { Excreted } \\
\text { Biomolecules }\end{array}$ & $\begin{array}{c}\text { Co NPs in TW } \\
+ \text { Algae + Excreted } \\
\text { Biomolecules }\end{array}$ & Peak Assignments \\
\hline 1635 & 1644 & & 1670 & 1664 & 1672 & Amide I [34,35] \\
\hline 1544 & 1588 & 1582 & 1562 & 1568 & 1564 & $\begin{array}{c}\text { Amide } \\
\mathrm{II} / \text { asymmetric } \\
\mathrm{COO}^{-} \text {/asymmetric } \\
\mathrm{CO}_{3}{ }^{2-}[26,34,35]\end{array}$ \\
\hline \multirow[t]{3}{*}{1454} & & & 1500 & & 1494 & $\mathrm{CH}_{2}$ bending [34] \\
\hline & & 1425 & & & & $\begin{array}{c}\mathrm{CH}_{2} \text { Bend- } \\
\text { ing/asymmetric } \\
\mathrm{CO}_{3}{ }^{2-}[26]\end{array}$ \\
\hline & 1392 & 1385 & 1384 & 1385 & 1387 & $\begin{array}{c}\text { Symmetric } \\
\mathrm{COO}^{-} / \text {Amide } \\
\mathrm{III} / \text { asymmetric } \\
\mathrm{CO}_{3}{ }^{2-}[26,34]\end{array}$ \\
\hline \multirow[t]{2}{*}{$\begin{array}{c}1075,1047 \\
1028\end{array}$} & 1147, 1063, 1001 & & 1043 & 1032 & 1046 & $\begin{array}{c}\mathrm{C}-\mathrm{O}-\mathrm{C}, \mathrm{C}-\mathrm{OH}, \\
\mathrm{C}-\mathrm{O}, \mathrm{C}-\mathrm{C} \\
\text { stretching }[29]\end{array}$ \\
\hline & & 1060 & 1060 & 1060 & 1060 & $\begin{array}{c}\text { Symmetric } \mathrm{CO}_{3}{ }^{2-} \\
{[26]}\end{array}$ \\
\hline
\end{tabular}

Collected spectra after $2 \mathrm{~h}$ were comparable to the spectra acquired after $5 \mathrm{~min}$ for Co NPs in TW with algae, even though the relative intensities were different. This indicates small changes in the relative abundances of adsorbed biomolecules. For example, increased absorbances were observed for the functional groups related to the band at $1584 \mathrm{~cm}^{-1}$ (e.g., amide II, carboxylate) and at $\approx 1040 \mathrm{~cm}^{-1}$ (e.g., $\mathrm{CO}_{3}{ }^{2-}, \mathrm{C}-\mathrm{O}$ ). This may be attributed to an exchange of smaller biomolecules with larger molecules, e.g., polysaccharides that have higher affinity to the Co NPs. In addition, increased absorbance was observed for the vibrational band at $1032 \mathrm{~cm}^{-1}$ in TW containing excreted biomolecules. This provides evidence for increased adsorption of carbonate and/or biomolecules containing $\mathrm{C}-\mathrm{O}-\mathrm{C}$, $\mathrm{C}-\mathrm{O}$, or $\mathrm{C}-\mathrm{OH}$ functional groups, e.g., polysaccharides. The spectrum acquired in TW containing both algae and excreted biomolecules was in terms of the adsorption of species onto the Co NPs similar to the findings after $5 \mathrm{~min}$, i.e., similar to observations with pure algae and the excreted biomolecule solutions. However, a small yet notable difference was evident with the presence of a relatively weak band at $\approx 1494 \mathrm{~cm}^{-1}$ which was only observed in the spectra of both the pure algae solution and in TW containing both algae and excreted biomolecules. Similar band positions suggest that if mixed, biomolecules from both solutions are adsorbed onto the Co NPs, as observed in the spectra of exposures in pure solutions of algae and excreted biomolecules, respectively.

After $2 \mathrm{~h}$ exposure, the Co NP film was rinsed with pure water to, if possible, remove loosely adsorbed biomolecules. This procedure resulted in only small changes of the main vibrational bands, as shown in Figure 2B,D, indicative of the strong adsorption of species from algae and excreted biomolecules. Exposures in TW with the excreted biomolecules showed the most prominent changes upon rinsing with a substantial reduction in the absorbance of the vibrational bands at $1032 \mathrm{~cm}^{-1}$. These observations are indicative of the desorption of adsorbed $\mathrm{CO}_{3}{ }^{2-}$ /C-O-containing molecules (Table 1). 
Overall, the ATR-FTIR results show that various biomolecules, carboxylate-rich compounds and probably carbonates adsorb to the Co NPs. The presence of excreted biomolecules in the algae solution did not largely influence the adsorption of the constituents from the algae solution. The observations of different biomolecules adsorbing onto the Co NPs, forming an ecocorona, are in accordance with the general trend observed for different NPs in solutions containing various natural organic molecules [36-38].

Zeta potential measurements were performed to assess whether the adsorption of the different biomolecules onto the Co NPs would result in any measurable changes in apparent surface potential at the outermost solid/liquid interface in the solution. The results are presented in Figure 3 for the Co NPs in TW containing algae and excreted biomolecules and in TW containing algae with and without the presence of excreted biomolecules. The algae in TW were slightly negatively charged $(-13 \pm 2 \mathrm{mV})$, which was expected due to the high content of polysaccharides and other carboxylate-containing molecules on the cell surface of algae. A slightly more negative potential $(-17 \pm 2 \mathrm{mV})$ was determined upon adding the excreted biomolecules to TW containing algae, possibly indicative of the complexation of some negatively charged constituents with the algae. The determined zeta potential of the Co NPs in TW ( $\mathrm{pH} 10.5$ ) was $-27 \pm 1 \mathrm{mV}$, a more negative value compared to previous findings of the same $\mathrm{Co}$ NPs in $10 \mathrm{mM} \mathrm{NaCl}$ at pH 6 [21]. Combined with the ATR/FTIR findings (Figure 2A), it is evident that the adsorption/coordination of $\mathrm{CO}_{3}{ }^{2-}$ with the Co NPs leads to a more negatively charged surface. The addition of excreted biomolecules into TW and their concomitant adsorption (Figure 2C) did not result in any significant change in zeta potential $(-23 \pm 1 \mathrm{mV})$.

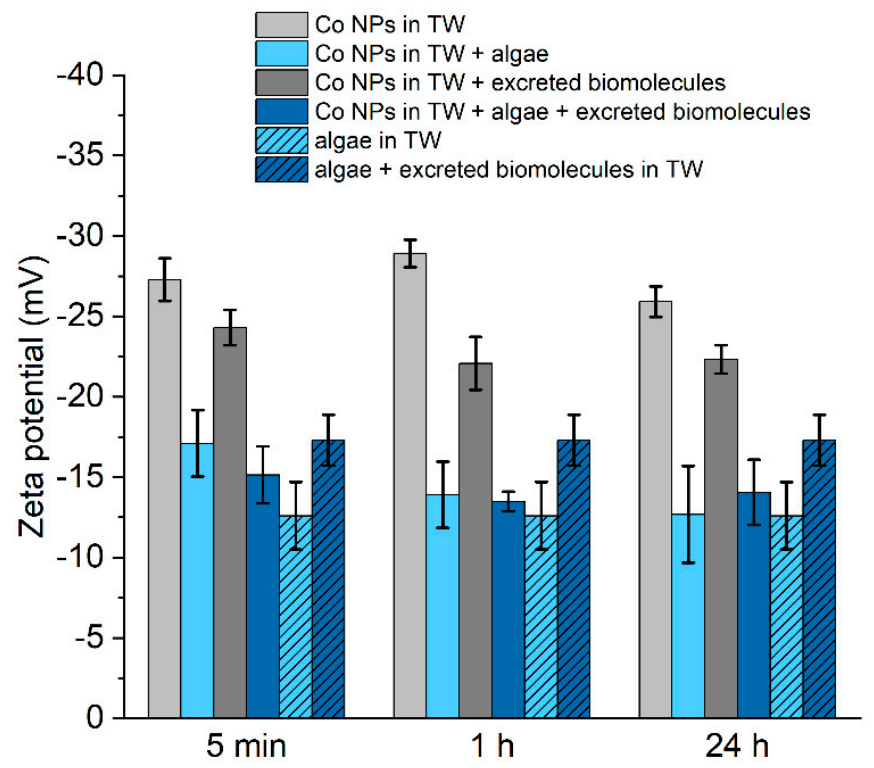

Figure 3. Apparent surface potential (Zeta potential) of Co NPs in TW, Co NPs in TW containing algae, Co NPs in TW with excreted biomolecules and Co NPs in TW with both algae and excreted biomolecules. For comparison, results without the Co NPs are included, i.e., for algae in TW and excreted biomolecules in TW. The zeta potential was determined after $5 \mathrm{~min}, 1 \mathrm{~h}$, and $24 \mathrm{~h}$. The error bars represent the standard deviation of three individual replicates for each condition.

The addition of algae to the TW resulted in a less negative surface charge of the Co $\mathrm{NPs}(17 \pm 2 \mathrm{mV})$ compared to the TW only $(-27 \pm 1 \mathrm{mV})$. Any further addition of excreted biomolecules to the algae solution did not significantly change the zeta potential. The zeta potential of the Co NPs in the algae solution (with and without excreted biomolecules) was similar to the pure algae solution (without Co NPs). This indicates that the adsorbed layer mainly consists of constituents from algae, e.g., polysaccharides, which agree with the ATR-FTIR findings. 
Overall, the results showed a lack of significant differences in zeta potential even after extended exposure periods (24 h).

\subsubsection{The Fate of Co NPs in the First Trophic Level}

Any transformation of Co NPs in the presence of algae and excreted biomolecules in solution (TW in this study) might influence their potential transfer to the next trophic level. These conditions are schematically illustrated in Figure 4 and include; (i) free $\mathrm{Co}^{2+}$ ions released from the NPs as well as labile and more strongly bonded complexes formed with TW- and excreted biomolecule constituents; (ii) complexes formed between released $\mathrm{Co}^{2+}$ ions and algae; (iii) Co NPs in solution, including their agglomerates; (iv) heteroagglomerates of Co NPs and algae; and (v) sedimented Co NPs. The distribution between Co NPs and ions/complexes will affect their potential to be transferred to the next trophic level $[17,36]$ (in this study, represented by zooplankton feeding on algae).

\section{Co NP Dissolution}

Figure 5 presents the total amounts of released Co from the Co NPs in TW containing algae with and without the addition of excreted biomolecules. The results clearly show very limited amounts of released $\mathrm{Co}$ in the solution $(<1 \%)$ compared with the total amount of added Co NPs. These results indicate that the dissolution at given conditions will not substantially affect the trophic transfer of the Co NPs. A statistically significant increase in the extent of Co dissolution $(p<0.05)$ was observed after both $1 \mathrm{~h}(0.2 \%)$ and $24 \mathrm{~h}(0.9 \%)$ for the exposures in TW containing both algae and excreted biomolecules, Figure 5 (right). The adsorption of excreted biomolecules onto the Co NP surfaces, as observed by means of ATR/FTIR (Figure 2C), evidently results in changes in the surface reactivity of the Co NPs. Adsorbed species of smaller size (e.g., excreted biomolecules) can over time be replaced by larger constituents of the algae that have higher affinity to the surface and influence the extent of dissolution of the Co NPs [37,39].

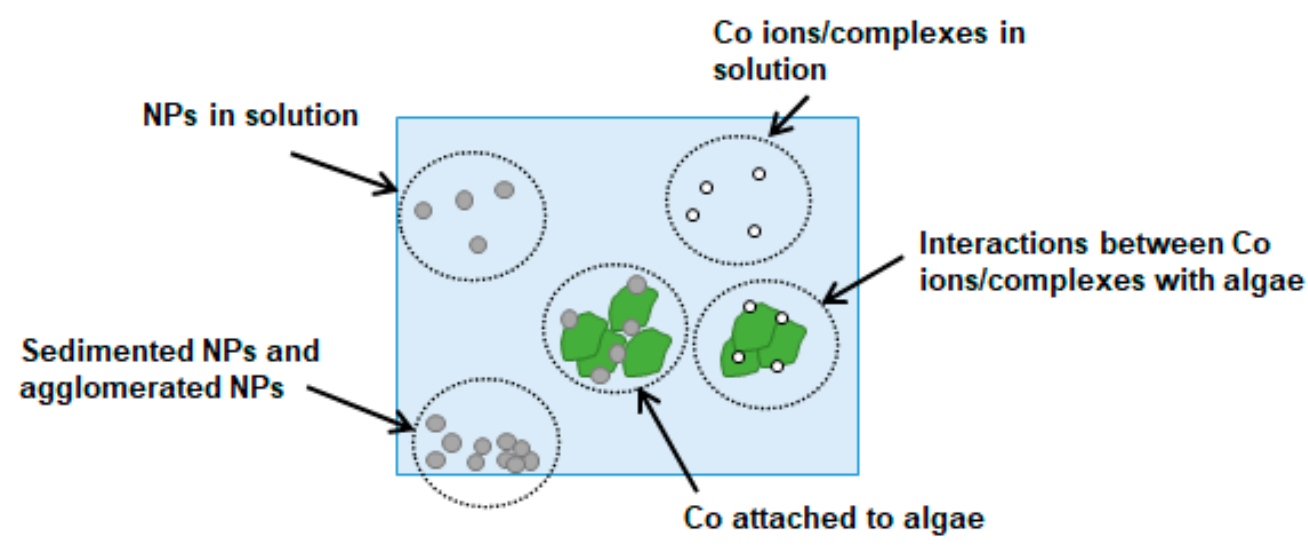

Figure 4. A schematic illustration of plausible processes that can take place in TW contacting algae and excreted biomolecules.

In TW containing algae, the extent of Co NP dissolution was substantially less compared to, for example, the release of Co at physiological conditions for the same Co NPs [21]. The main reason is attributed to a higher $\mathrm{pH}$ in TW containing algae ( $\mathrm{pH} 10.5)$ compared with pH 7.4 at physiological conditions and the presence of substantially lower amounts of inorganic species in TW (Table S1) compared with the amounts of phosphate and chloride in phosphate-buffered saline [21].

Interactions between Released Co Ions and Algae

Released Co ions from the Co NPs may interact and bind to the algae, as schematically depicted in Figure 4. However, since centrifugation was employed before determining the released amount of $\mathrm{Co}$ in the solution (Figure 5), it cannot be excluded that the actual 
released amount of Co was higher but not measured due to binding with algae components. To investigate this further, TW with algae was spiked with known concentrations of $\mathrm{Co}^{2+}$ ions ( 44 and $440 \mu \mathrm{g} / \mathrm{L}$ ) for $5 \mathrm{~min}, 1 \mathrm{~h}$ and 1 day to assess the fraction that would bind to the algae. After exposure, the algae were removed from the solution by centrifugation, and the remaining concentration of $\mathrm{Co}$ in the solution was measured. The results showed that between 1 and 17\% (a slightly increased fraction with time, Figure S1) of the added Co ion concentrations were removed from the solution due to bonding/complexation with the algae. No differences were discerned for the different $\mathrm{Co}^{2+}$ ion concentrations. The results clearly show that the extent of binding/complexation of released Co ions from the Co NPs to algae is small, and the contribution is minor since $<1 \%$ (based on mass) of the NPs were dissolved within the investigated exposure time frames (Figure 5 and Figure S1).

Co NPs in Solution and Heteroagglomeration between Co NPs and Algae

Particle size distribution measurements using DLS were performed in TW and TW containing algae (both with and without the addition of excreted biomolecules) to determine whether the Co NPs remained in solution up to $24 \mathrm{~h}$. Unfortunately, low scattered light intensities of the NP suspensions were observed already after 5 min (Table S2), which prohibited the determination of any particle size distributions. These results indicate the rapid agglomeration and settlement (sedimentation) of the majority of the Co NPs at the bottom of the test vessel. Hence, the surface interactions between Co NPs and algae were not insufficient to retain the Co NPs in solution (i.e., prevent sedimentation), as can be seen in Figure 2.

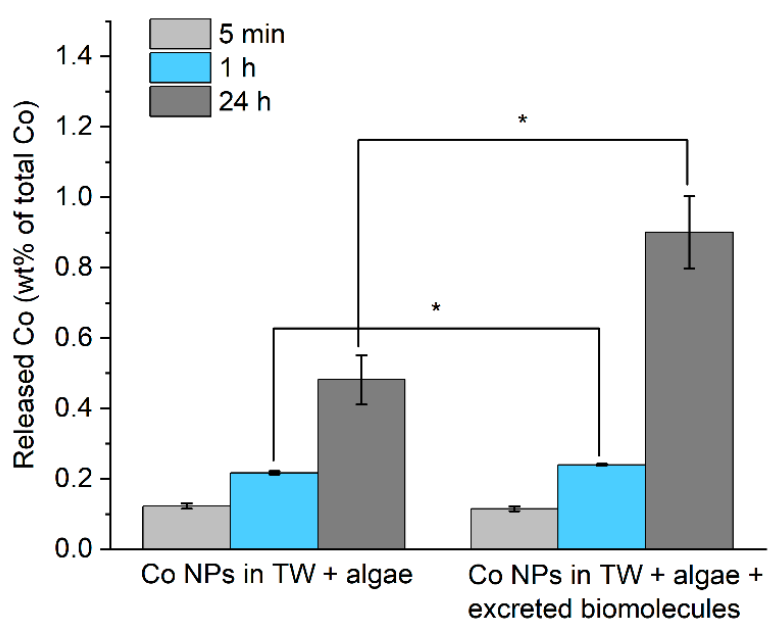

Figure 5. Released amounts of Co in the solution from Co NPs $(6.2 \mathrm{mg} / \mathrm{L})$ in TW containing algae $(450 \mu \mathrm{g} / \mathrm{L})$ and in TW containing both algae and excreted biomolecules $(0.64 \mathrm{mg} / \mathrm{L} \mathrm{TOC})$. The $\mathrm{pH}$ was 10.5. The asterisks indicate a statistically significant difference ( $p<0.05$, Student's $t$-test). Error bars represent the standard deviation of three individual replicates.

To estimate the extent of heteroagglomeration between the Co NPs and algae, the Co NPs were mixed with TW and with TW containing algae and excreted biomolecules followed by centrifugation (to separate the algae) after $5 \mathrm{~min}, 1 \mathrm{~h}$, and $24 \mathrm{~h}$ of exposure, Figure 6. The total concentration of $\mathrm{Co}$ in the supernatant was then analysed with AAS as a measure of the total amount of Co in the solution, i.e., released Co ions/complexes and Co NPs. The fractions of Co NPs/algae heteroagglomerates and of sedimented Co NPs (i.e., the fraction removed by the centrifugation step) were then calculated based on the initial Co NP loading, Figure 6. 
Some extent of heteroagglomeration between Co NPs and algae was suggested to take place concluded from the larger reduction in Co in solution observed in TW containing algae compared with TW only. However, the difference between the amount of sedimented Co NPs and the amount of heteroagglomerated Co NPs/algae was less than $5 \%$. Together with the PCCS findings that elucidated rapid and substantial sedimentation in solution, the generated results imply that precise numbers on the extent of Co NPs/algae heteroagglomeration are difficult to obtain from these experiments. The ATR-FTIR adsorption studies showed increased surface interactions between the algae and the Co NP films with time, which suggest a thickening of adsorbed algae constituents onto the Co NP surfaces, Figure 2. This might be one reason for the low extent of $\mathrm{Co} \mathrm{NP} /$ algae heteroagglomerates since the adsorption of algae constituents and the Co NP surfaces need time to form a thicker layer, whereas the sedimentation of the Co NPs was rapid.

The addition of excreted biomolecules to the algae solutions resulted in a reduced extent of particle sedimentation and algae/Co NP heteroagglomeration. This effect was statistically significant $(p<0.05)$ for the $5 \mathrm{~min}$ and $1 \mathrm{~h}$ exposure. However, a similar fraction of sedimented and algae/Co NP heteroagglomerates was observed in TW containing the excreted biomolecules after $24 \mathrm{~h}$ exposure as observed in TW. These results show that, even though both excreted biomolecules and algae adsorb onto the Co NPs (ATR-FTIR, Figure 2), it is evident that the presence of excreted biomolecules had a negligible effect on the extent of heteroagglomeration between Co NPs and algae.

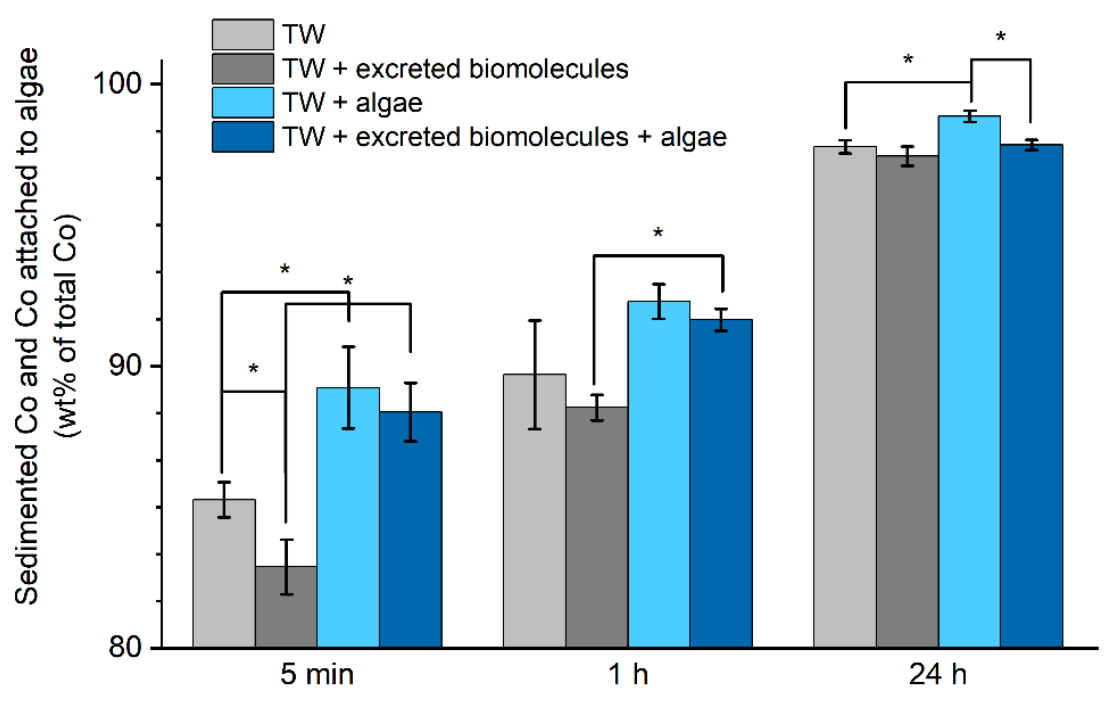

Figure 6. Fraction of sedimented Co NPs and Co NPs/algae heteroagglomerates for Co NPs $(6.2 \mathrm{mg} / \mathrm{L})$ in TW, in TW containing excreted biomolecules $(0.64 \mathrm{mg} / \mathrm{L} \mathrm{TOC})$, in TW containing algae $(450 \mu \mathrm{g} / \mathrm{L})$, and in TW containing both algae and excreted biomolecules after centrifugation (1 min at $2000 \times g$ ). The asterisks indicate statistically significant results (Student's $t$-test, $p<0.05$ ). Error bars represent the standard deviation of three individual replicates.

In order to validate the relevance of the heteroagglomeration experiments and results obtained for the Co NPs and algae, similar experiments were performed for Au NPs ( $3.9 \mathrm{mg} / \mathrm{L}$, citrated coated) for which heteroagglomeration with algae is known to take place $[16,17]$. The results were investigated using UV-Vis. The spectra from Au NPs in TW after the removal of algae/Au NPs heteroagglomerates are presented in Figure 7A, and their fraction compared with the initial absorbance at the start of the exposure is shown in Figure 7B. The results show that $85-90 \%$ of the citrate coated Au NPs remained in solution, which was considerably more than observed for the Co NPs $(<15 \%)$. However, observed findings for the Au NPs are in line with previous findings [17], which corroborates that the heteroagglomeration process is highly material specific and higher for the Co NPs compared with the Au NPs due to lower stability in TW. 
Previous findings report the rapid heteroagglomeration between $\mathrm{CuO}$ NPs and algae cells [40], and similar observations have been reported for $\mathrm{Al}_{2} \mathrm{O}_{3}, \mathrm{TiO}_{2}$, and $\mathrm{SiO}_{2} \mathrm{NPs}_{\text {[41] }}$. $\mathrm{Ag}$ NPs have been shown to be more dispersed in the aquatic environment than Co NPs and more readily form heteroagglomerates with freshwater algae [42]. Organic matter, such as glutathione, is reported to adsorb to Ag NPs and at the same time stabilise and render them well dispersed in the solution [36]. In this study, the sedimentation of the Co NPs rapidly took place independently of the surface interactions with algae and excreted biomolecules (see adsorption studies, Figure 2). An explanation for the lack of observed colloidal stability of the Co NPs in this study may be related to the initial absence of a thick stabilising layer of biomolecules on the Co NP surface and the high attractive van der Waals forces for metal particles, which at given conditions, will most probably dominate the interaction between the NPs [23].

A

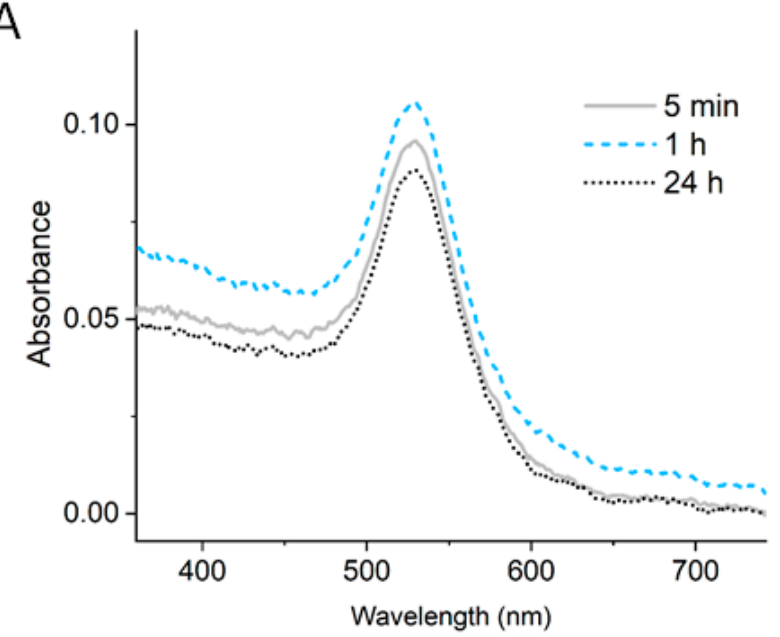

B

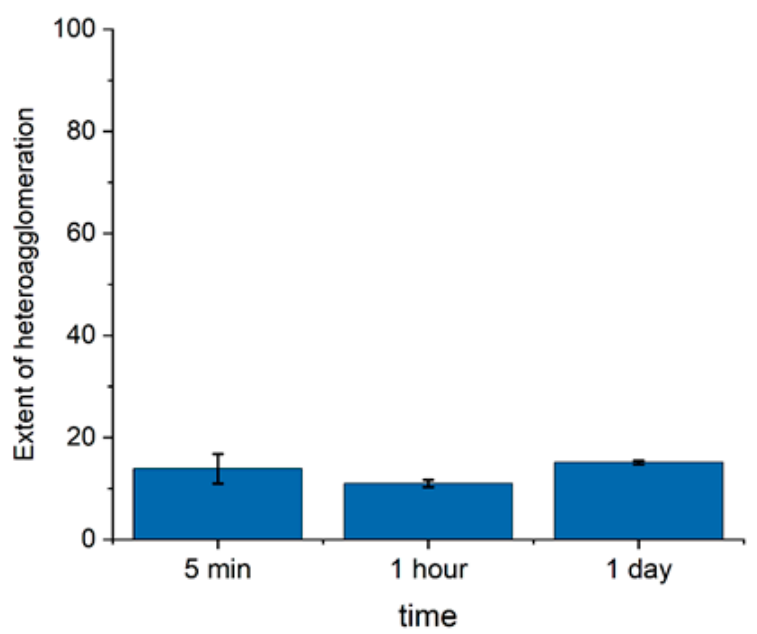

Figure 7. (A): UV-Vis spectra of Au NPs (3.9 mg/L) exposed in TW containing algae for $5 \mathrm{~min}, 1 \mathrm{~h}$ and $24 \mathrm{~h}$; and (B): fraction of heteroagglomerated Au NPs compared with the initial absorbance at the start of the exposure. The algae were separated (centrifugated) prior to analysis.

Overall, the fractioning of Co NPs in contact with algae, as schematically depicted in Figure 4, can be concluded as follows: less than $1 \%$ of the mass of the Co NPs (nominal loading of $6.2 \mathrm{mg} / \mathrm{L}$ ) was dissolved as "free" Co ions forming complexes and the extent of Co ion complexation to algae was even less. The substantial sedimentation of the Co NPs was evident, with more than $80 \%$ of the Co NPs already settled within 5 min, a fraction that increased with time. The adsorption of excreted biomolecules onto the Co NP surfaces resulted in the slight enhancement of the Co dissolution. However, it did not influence the extent or the rate of sedimentation, or the extent of heteroagglomeration with algae. Only $0.4-5 \%$ of the total amount of added Co NPs formed heteroagglomerates with algae in solution, a fraction which in the food web may hence be transferred to $D$. magna via ingestion.

\subsection{Trophic Level 2: Daphnia Magna}

Algae exposed to Co NPs for $24 \mathrm{~h}$, see the previous section, were subsequently fed to D. magna for another $24 \mathrm{~h}$. The total uptake of Co (ions, complexes, NPs) by D. magna, including control samples (D. magna feeding on algae without Co NPs), is presented in Figure 8. Approximately 300 times more Co was observed in the D. magna exposed to Co NPs compared to the control samples. No significant difference in Co uptake was observed in the presence of excreted biomolecules $(p=0.11)$. As elucidated above, the Co NPs and algae can form heteroagglomerates, even though the fraction was estimated to be very small (0.4-5\% of the total Co loading). Since D. magna feed on algae, this amount could be sufficient to explain the observed levels of Co. D. magna that potentially filter "free" Co 
NPs, and Co NP agglomerates directly from solution in addition to the ingestion of Co NPs integrated via the food (algae) [43]. However, previous studies have shown that the food uptake route via algae is generally more efficient than any uptake directly from the water [20].

The lack of influence of excreted biomolecules on the uptake of Co NPs is in line with the results presented in Figure 6, showing only small (or no) differences in the extent of heteroagglomeration between the Co NPs and the algae, in addition to minor effects on the extent of sedimented NPs when adding excreted biomolecules. It should be noted that $D$. magna will excrete additional biomolecules into the TW solution during the feeding [20]. Such an addition of excreted biomolecules has been shown to reduce the uptake of polystyrene NPs in D. magna [20]. Compared to this study, the main difference was that heteroagglomeration occurs between the Co NPs and the algae, thereby possibly making the addition of excreted molecules of less importance for the uptake (see Figure 8).

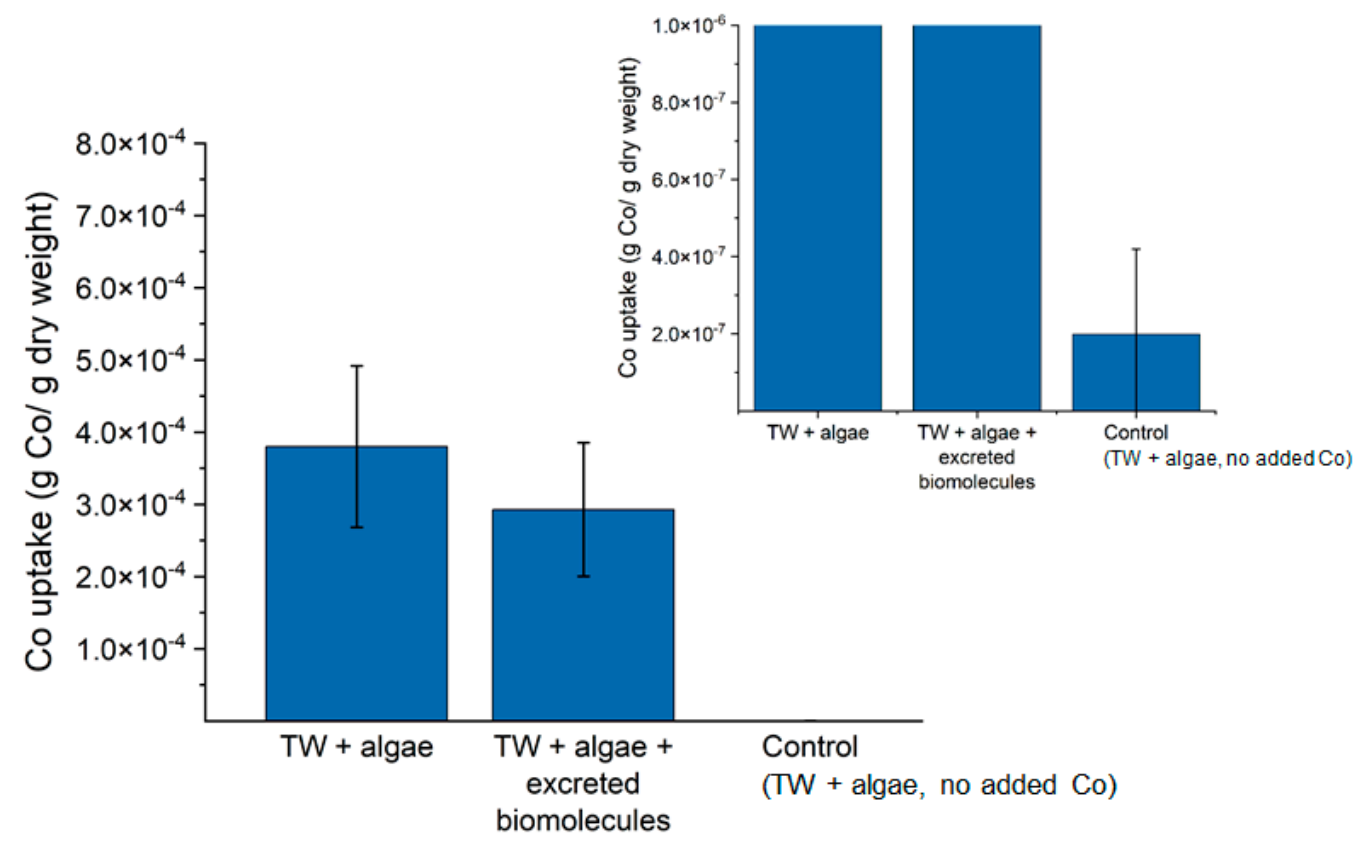

Figure 8. Co uptake by D. magna given as g Co per g dry body weight. Inset: magnified figure to show the results of the control sample. The results include $20 \mathrm{D}$. magna individuals in each sample and 8 samples for each exposure condition (TW + algae, TW + algae + excreted biomolecules and control), i.e., a total of 160 individuals per solution tested for Co uptake. Error bars represent the standard deviation of three individual replicates.

D. magna has, in a previous study, been shown to be able to take up tungsten carbide (WC) NPs $(10 \mathrm{mg} / \mathrm{L})$ when feeding on algae $(0.02 \mathrm{~g} \mathrm{WC} / \mathrm{g}$ dry weight after $24 \mathrm{~h})$ [44]. This uptake was approximately 20 times higher than that observed for the Co NPs investigated in this study. Rapid agglomeration and sedimentation were also evident for the WC NPs, even if some WC NPs could be observed in solution (by light scattering) after $24 \mathrm{~h}$. No Co NPs were discerned by DLS (PCCS) in this study after the same time period. The difference in uptake between the WC and the Co NPs may be explained by their individual surface properties, with the former being less prone to adsorb natural organic matter [45]. Observed sedimentation rates were also different, findings of importance for the possible uptake by D. magna [45]. 
A considerably larger extent of heteroagglomeration of the citrate stabilised Au NPs than the Co NPs were presented in Figure 7. Literature findings also show a higher uptake of Au NPs by D. magna $\left(8.3 \cdot 10^{-3}, 10.5 \cdot 10^{-3}\right.$ and $23.6 \cdot 10^{-3} \mathrm{~g} \mathrm{Au} / \mathrm{g}$ dry weight after $24 \mathrm{~h}$ feeding on algae for Au NPs stabilised with citrate, humic acid-HA, and polyhydroxyalkanoatePAH s [17]) compared to the findings for the Co NPs in this study $\left(3 \cdot 10^{-4} \mathrm{~g} \mathrm{Co} / \mathrm{dry}\right.$ weight after $24 \mathrm{~h}$ ). The uptake of the Au NPs changed to $2.5 \cdot 10^{-3}, 1.9 \cdot 10^{-3}$ and $3.1 \cdot 10^{-3} \mathrm{~g} \mathrm{Au} / \mathrm{g}$ dry weight after the depuration of the $D$. magna, which means that the surface chemistry of the Au NPs was not a key factor governing their uptake [17]. The lower uptake of the Co NPs in this study compared with the Au NPs can then possibly be explained by a lower extent of heteroagglomeration between the Co NPs and algae and a faster sedimentation rate of the Co NPs.

Since the Co NPs may dissolve and change their surface chemistry if ending up in the gastrointestinal tract of $D$. magna $[7,46]$, dissolution experiments were performed in simulated gastric fluid ( $\mathrm{pH} 7$, Figure 9A). In addition, dissolution experiments were also performed in simulated fish gut solution ( $\mathrm{pH} 4$, Figure 9B), as discussed below.

A

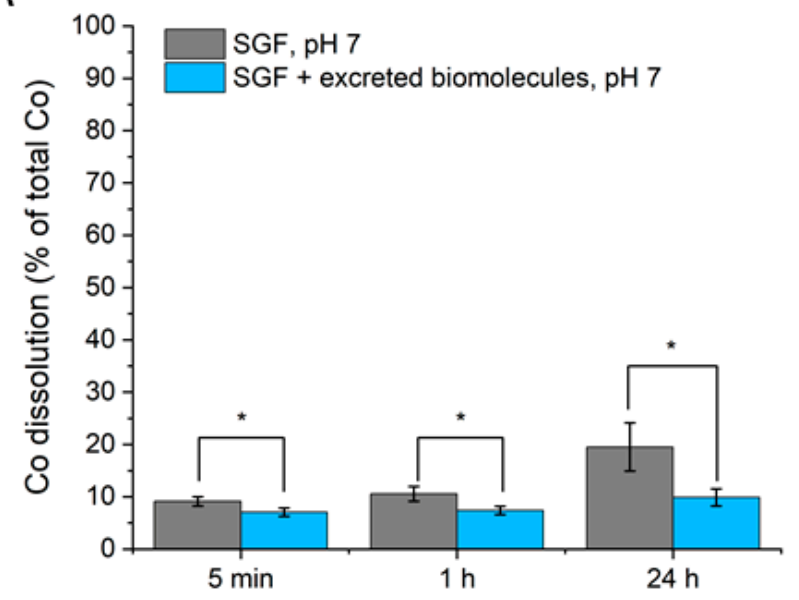

B

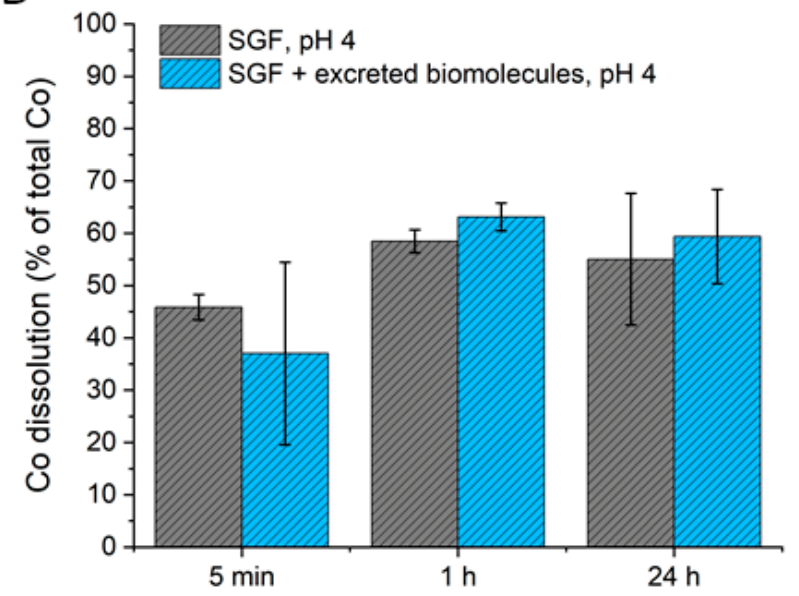

Figure 9. Co dissolution in simulated gastric fluid (SGF, $2 \mathrm{~g} / \mathrm{L}$ chlorides) for (A): D. magna (pH 7); and (B): fish (pH 4) in the absence and presence of excreted biomolecules. The mean Co NP loading was approximately $6.2 \mathrm{mg} / \mathrm{L}$. Error bars represent the standard deviation of three individual replicates. The asterisks indicate statistically significant differences $(p<0.05$, Student's $t$-test $)$.

The results showed substantially more Co dissolution at $\mathrm{pH} 7$ compared to the results in the algae-TW solutions of $\mathrm{pH} 10.5(<1 \%$, see Figure 5$)$. Thus, the results elucidate an effect of solution $\mathrm{pH}$ and of the presence of chlorides on the dissolution of the Co NPs. Conversely to findings in TW containing algae ( $\mathrm{pH}$ 10.5), the addition of excreted biomolecules resulted in a reduced dissolution of $\mathrm{Co}$ at $\mathrm{pH}$ 7. Clearly, the solution $\mathrm{pH}$ can affect the dissolution process via different surface interactions due to, for example, the protonation/deprotonation and adsorption of functional groups of the excreted constituents. In addition, other biomolecules and ligands within the D. magna may, under real conditions, influence the fate of the Co NPs. However, the findings in this study indicate that excreted biomolecules adsorbed and/or heteroagglomerated to Co NPs may influence their dissolution properties at higher trophic levels.

Overall, it can be concluded that D. magna can take up Co NPs, but this uptake is low compared with other NPs (e.g., WC, Au). The presence of excreted biomolecules to TW containing algae did not have any substantial effect on the uptake. This could be connected to similar surface interactions between algae and excreted biomolecules with the Co NPs (Figures 2 and 3). The extent of the total dissolution of the Co NPs under simulated conditions in the gastrointestinal tract of D. magna was determined at $10-20 \%$ after $24 \mathrm{~h}$ of 
exposure. This means that most of the ingested Co NPs transferred to the gastrointestinal tract of D. magna would remain as particles if transferred to the next trophic level.

\subsection{Trophic Level 3: Crucian Carp}

Figure 10 presents the Co uptake by Crucian carps feeding on D. magna that were pre-fed with algae and also pre-fed with Co NPs (Figure 8). The uptake in the fish hence represents the total Co concentration, including Co NPs as well as dissolved Co NPs forming complexes, and ionic Co. The Co content in the control fish (no Co NPs) was determined to $\approx 10^{-7} \mathrm{~g} \mathrm{Co} / \mathrm{g}$ dry weight. This corresponds to a concentration within or below the Co quantification limit of the AAS method and similar to D. magna control samples (see Figure 8). The Co contents in the stomachs and intestines of the fish (Figure 10A,D) are shown since Co was introduced as food (D. magna) to the fish. The Co uptake was significantly higher than the controls in the fish intestines (Figure 10C,D), both with and without excreted biomolecules in the feeding solution $(p<0.05)$. The mean values of the Co uptake were higher in the stomach of fish feeding on Co-containing D. magna compared with the control, although the observed differences were not statistically significant. In all cases, the uptake of Co in the muscles, brain, blood serum and blood cells was very similar to the control samples (Supporting Information, Figure S2). The uptake of Co in the gills (Figure 10E,F) was also at the same levels as the control samples, which suggests that the uptake of Co NPs was mainly via the food (D. magna) rather than from Co NPs in the water. Overall, the results suggest that the fish do take up some of the Co NPs present in the $D$. magna, but statistically reliable evidence for this was only observed for the intestine.

When calculating the bioaccumulation factor as the Co uptake by fish ( $\mathrm{g} \mathrm{Co} / \mathrm{g}$ dry weight) divided by the corresponding uptake in D. magna $[45,47]$, it was evident that no bioaccumulation of $\mathrm{Co}$ in the trophic transfer was observed for the investigated organs or parts of the fish. The Co uptake was approximately 100 times larger in D. magna (Figure 8) compared with the Crucian carp on a weight basis (Figure 10). Similar findings have previously been reported for the uptake of Co ions in fish [47].

Co NPs that may reach the gut of the fish (Crucian carp) will most likely dissolve, as $\approx 60 \%$ of the Co NPs dissolved within $1 \mathrm{~h}$ in simulated gastric fluid relevant for fish $(\mathrm{pH}$ 4) [48] (Figure 9B). Similar findings have been reported for fish (three-spined stickleback (Gasterosteus aculeatus)) feeding on worms (Tubiflex tubiflex) that had taken up CuO NPs [13].

The presence of excreted biomolecules, which adsorbed (forming an ecocorona) at the surfaces of the Co NPs (Figure 2), did not change the extent of uptake by fish. These findings are in line with the adsorption studies at the first trophic level (algae), showing similar ecocorona surface constituents on the Co NPs in TW containing algae with and without excreted biomolecules (Figure 2). Whether adsorbed excreted biomolecules and algae species remain if the Co NPs reach the fish can only be speculated since exchange with other biomolecules, or dissolution can change the surface composition [7]. However, rinsing with pure water left the majority of the adsorbed molecules at the surface (Figure 2). Similar observations are reported in the literature, e.g., humic acid remains adsorbed on $\mathrm{TiO}_{2}$ NPs upon interaction with proteins (bovine serum albumin) [34].

Overall, the transfer of Co NPs from D. magna to fish organs did not result in any bioaccumulation of Co. However, the amount of Co per $\mathrm{g}$ of fish organs showed differences in the stomach and intestine compared with the controls, whereas no significant differences were observed for the other selected fish organs. Approximately $60 \%$ Co of the Co NP mass was dissolved into the solution within $1 \mathrm{~h}$ at $\mathrm{pH} 4$ (Figure 9B), corresponding to the $\mathrm{pH}$ of the fish stomach. 

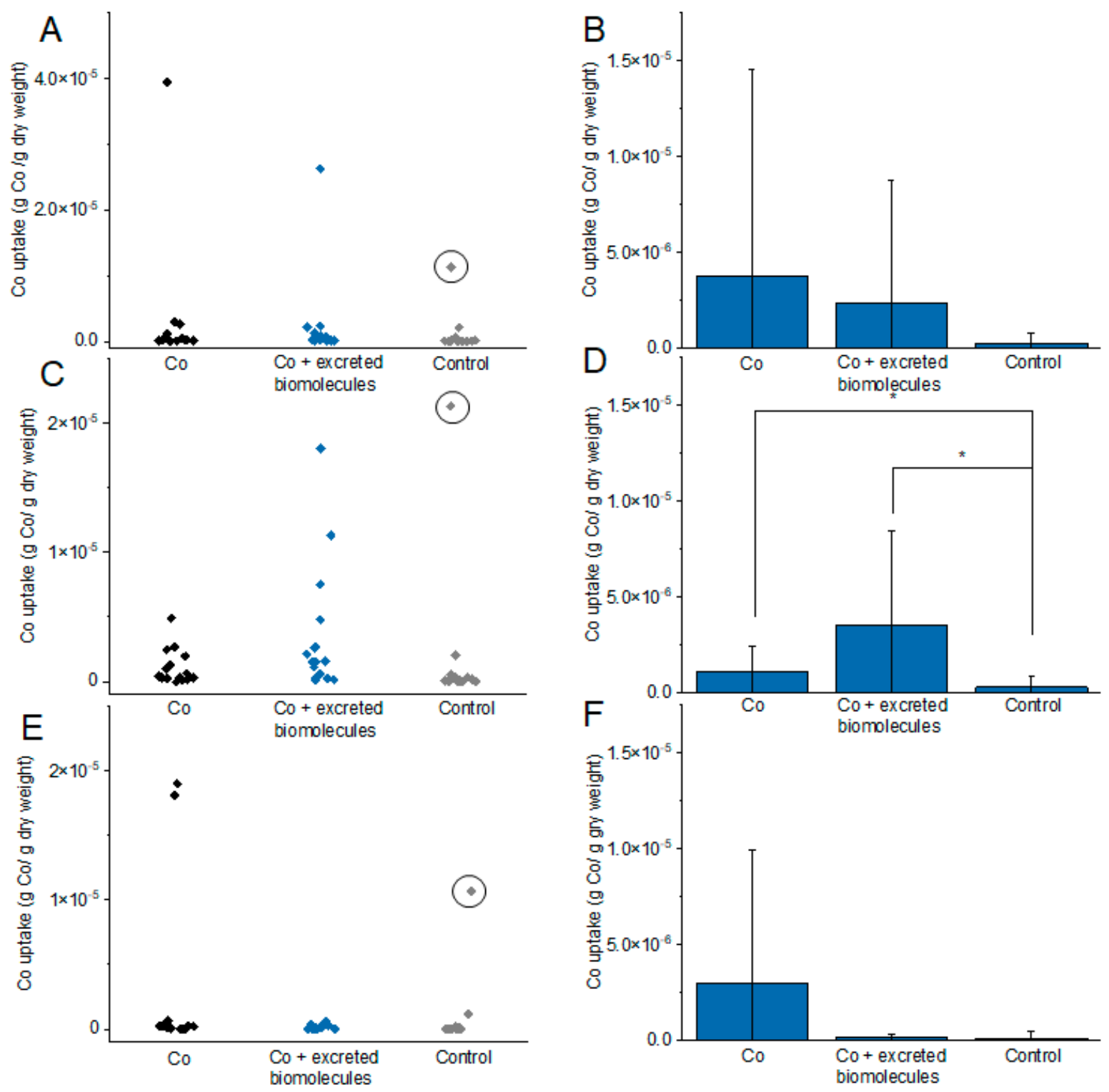

Figure 10. Co uptake in the fish stomach and intestine, calculated as g Co per g dry body organ weight: (A) results from all samples of Co uptake in fish stomachs (each point is an individual fish); (B) mean values of Co uptake in the fish stomach; (C) results from all samples of Co uptake in fish intestines (each point is an individual fish); (D) mean values of Co uptake in the intestine; (E) results from all samples of Co uptake in fish gills (each point is an individual fish); and (F) mean values of Co uptake in fish gills. The error bars are the values of one standard deviation. The asterisks indicate statistically significant differences ( $p<0.05$, Student's $t$-test). The point marked with a circle is an outlier checked by the Grubbs test [49]. This value was removed when calculating the mean values. The fish were fed 8 times during 15 days, i.e., exposure to Co NPs every second day. Error bars represent the standard deviation of three individual replicates.

\section{Summary}

This study investigated the influence of interactions between engineered Co NPs with algae and naturally excreted biomolecules from zooplankton (D. magna) in synthetic tap water (TW) on their potential for food web transfer and bioaccumulation via three trophic levels: algae (Scendesmus sp.), zooplankton (D. magna) and fish (Crucian carp). Even though the adsorption studies by means of ATR-FTIR indicated some surface interactions between the NPs and algae, a low extent of heteroagglomeration between the Co NPs and algae $(0.4-5 \%)$ was taking place in the first trophic level (algae). This was predominantly 
attributed to extensive rapid Co NP agglomeration and sedimentation due to strong van der Waal forces.

The presence of excreted biomolecules in TW containing algae resulted in additional surface adsorption, though these interactions neither affected the extent of heteroagglomeration between the Co NPs and the algae, nor the uptake of Co in either D. magna or fish. Less than $0.5 \%$ of the Co NP mass dissolved within $24 \mathrm{~h}$ in TW with algae and was only slightly enhanced $(<1.2 \%)$ by the presence of excreted biomolecules.

The uptake of Co NPs by D. magna via the ingestion of algae was small and not influenced by the presence of excreted biomolecules. The dissolved fraction of the Co NPs was small in the simulated gastric tract (5-20\%). Even though Co was taken up by the zooplankton when fed with algae exposed to Co NPs, no bioaccumulation was observed for any of the trophic levels, as evident from the low amounts of detectable Co per mass in fish compared with D. magna. The uptake in fish was predominantly via the ingestion of D. magna as Co was only observed in the gut of the fish. Ingested Co NPs were readily dissolved upon uptake as elucidated in simulated gastrointestinal tract fluids (35-45\% within $5 \mathrm{~min}$ and $55-65 \%$ after $24 \mathrm{~h}$ ).

The results show that environmental interactions with algae and natural biomolecules (here excreted biomolecules from zooplankton) change the characteristics of engineered Co NPs as a result of adsorption, heteroagglomeration and dissolution (e.g., in the gastrointestinal tracts). This emphasises the importance of performing environmental risk assessments on weathered NPs rather than on pristine engineered particles.

Supplementary Materials: The following results are available online at https:/ / www.mdpi.com/ article/10.3390/applnano2030014/s1, Figure S1: Amount of Co ions (wt \%) remaining in solution after removing algae from the solution for two different Co-ion loadings; Figure S2: Co uptake in fish organs; Table S1: Composition of tap water (TW) used in this study; Table S2: Changes in scattered light intensity (kcounts/s) with time for Co NP TW suspensions containing algae and algae + excreted biomolecules.

Author Contributions: Conceptualisation, T.C., E.B. and I.O.; investigation, N.M. and J.H. (particle characterisation, adsorption and metal release), M.T.E. and E.K. (exposure of Co NPs to D. magna and fish); writing - original draft preparation, N.M., J.H. and M.T.E.; writing-review and editing, all authors.; supervision, L.-A.H., T.C., E.B. and I.O.; funding acquisition, L.-A.H., T.C. and I.O. All authors have read and agreed to the published version of the manuscript.

Funding: This work forms part of the Mistra Environmental Nanosafety program. The financial support from Mistra (Stiftelsen för Miljöstrategisk Forskning) is greatly acknowledged.

Institutional Review Board Statement: The study was conducted according to the guidelines of the Declaration of Helsinki, and approved by the Institutional Review Board (or Ethics Committee) of the Swedish Board of Agriculture (protocol code M 133-16, applies until 2021) according to the current laws in Sweden.

Informed Consent Statement: Not applicable.

Data Availability Statement: Not applicable.

Acknowledgments: Klara Gustin Mossegård, Karolinska Institute is kindly acknowledged for assistance with the digestion of fish.

Conflicts of Interest: The authors declare no conflict of interest.

\section{References}

1. Wiesner, M.R.; Lowry, G.V.; Jones, K.L.; Hochella, J.M.F.; Di Giulio, R.T.; Casman, E.; Bernhardt, E.S. Decreasing uncertainties in assessing environmental exposure, risk, and ecological implications of nanomaterials. Environ. Sci. Technol. 2009, 43, 6458-6462. [CrossRef] [PubMed]

2. Vance, M.E.; Kuiken, T.; Vejerano, E.P.; McGinnis, S.P.; Hochella, M.F., Jr.; Rejeski, D.; Hull, M.S. Nanotechnology in the real world: Redeveloping the nanomaterial consumer products inventory. Beilstein J. Nanotechnol. 2015, 6, 1769-1780. [CrossRef] [PubMed] 
3. Hochella, M.F.; Mogk, D.W.; Ranville, J.; Allen, I.C.; Luther, G.W.; Marr, L.C.; McGrail, B.P.; Murayama, M.; Qafoku, N.P.; Rosso, K.M.; et al. Natural, incidental, and engineered nanomaterials and their impacts on the Earth system. Science 2019, 363, eaau8299. [CrossRef] [PubMed]

4. Oberdörster, G.; Oberdörster, E.; Oberdörster, J. Nanotoxicology: An emerging discipline evolving from studies of ultrafine particles. Environ. Health Perspect. 2005, 113, 823-839. [CrossRef]

5. Holden, P.A.; Nisbet, R.M.; Lenihan, H.S.; Miller, R.J.; Cherr, G.N.; Schimel, J.P.; Gardea-Torresdey, J.L. Ecological Nanotoxicology: Integrating nanomaterial hazard considerations across the subcellular, population, community, and ecosystems levels. Acc. Chem. Res. 2013, 46, 813-822. [CrossRef]

6. Gagné, F.; Gagnon, C.; Blaise, C. Aquatic nanotoxicology: A review. Curr. Top. Toxicol. 2007, 4, 51-64.

7. Tangaa, S.R.; Selck, H.; Winther-Nielsen, M.; Khan, F.R. Trophic transfer of metal-based nanoparticles in aquatic environments: A review and recommendations for future research focus. Environ. Sci. Nano 2016, 3, 966-981. [CrossRef]

8. Skjolding, L.M.; Sørensen, S.N.; Hartmann, N.B.; Hjorth, R.; Hansen, S.F.; Baun, A. Aquatic ecotoxicity testing of nanoparticlesThe quest to disclose nanoparticle effects. Angew. Chem. Int. Ed. 2016, 55, 15224-15239. [CrossRef]

9. Gophen, M.; Geller, W. Filter mesh size and food particle uptake by Daphnia. Oecologia 1984, 64, 408-412. [CrossRef]

10. Khan, F.R.; Kennaway, G.M.; Croteau, M.-N.; Dybowska, A.; Smith, B.D.; Nogueira, A.J.A.; Rainbow, P.S.; Luoma, S.N.; ValsamiJones, E. In Vivo retention of ingested Au NPs by Daphnia magna: No evidence for trans-epithelial alimentary uptake. Chemosphere 2014, 100, 97-104. [CrossRef]

11. Zhu, X.; Wang, J.; Zhang, X.; Chang, Y.; Chen, Y. Trophic transfer of $\mathrm{TiO}_{2}$ nanoparticles from daphnia to zebrafish in a simplified freshwater food chain. Chemosphere 2010, 79, 928-933. [CrossRef]

12. Chen, J.; Li, H.; Han, X.; Wei, X. Transmission and accumulation of nano- $\mathrm{TiO}_{2}$ in a 2-step food chain (Scenedesmus obliquus to Daphnia magna). Bull. Environ. Contam. Toxicol. 2015, 95, 145-149. [CrossRef] [PubMed]

13. Lammel, T.; Thit, A.; Mouneyrac, C.; Baun, A.; Sturve, J.; Selck, H. Trophic transfer of CuO NPs and dissolved Cu from sediment to worms to fish-A proof-of-concept study. Environ. Sci. Nano 2019, 6, 1140-1155. [CrossRef]

14. Kim, J.H.; Gibb, H.J.; Howe, P.D.; World Health Organization Chemical Safety Team; International Programme on Chemical Safety. Cobalt and Inorganic Cobalt Compounds/Prepared by James H. Kim, Herman J. Gibb, Paul D. Howe; World Health Organization: Geneva, Switzerland, 2006; ISBN 9789241530699.

15. Furberg, A.; Arvidsson, R.; Molander, S. Environmental life cycle assessment of cemented carbide (WC-Co) production. J. Clean. Prod. 2019, 209, 1126-1138. [CrossRef]

16. Barton, L.E.; Therezien, M.; Auffan, M.; Bottero, J.-Y.; Wiesner, M.R. Theory and methodology for determining nanoparticle affinity for heteroaggregation in environmental matrices using batch measurements. Environ. Eng. Sci. 2014, 31, 421-427. [CrossRef]

17. Geitner, N.K.; Marinakos, S.M.; Guo, C.; O’Brien, N.; Wiesner, M.R. Nanoparticle surface affinity as a predictor of trophic transfer. Environ. Sci. Technol. 2016, 50, 6663-6669. [CrossRef] [PubMed]

18. Wang, Z.; Zhang, L.; Zhao, J.; Xing, B. Environmental processes and toxicity of metallic nanoparticles in aquatic systems as affected by natural organic matter. Environ. Sci. Nano 2016, 3, 240-255. [CrossRef]

19. Ekvall, M.T.; Hedberg, J.; Odnevall Wallinder, I.; Hansson, L.-A.; Cedervall, T. Long-term effects of tungsten carbide (WC) nanoparticles in pelagic and benthic aquatic ecosystems. Nanotoxicology 2018, 12, 79-89. [CrossRef] [PubMed]

20. Nasser, F.; Constantinou, J.; Lynch, I. Nanomaterials in the environment acquire an "eco-corona" impacting their toxicity to Daphnia magna-A call for updating toxicity testing policies. Proteomics 2020, 20, 1800412. [CrossRef] [PubMed]

21. Mei, N.; Hedberg, J.; Odnevall Wallinder, I.; Blomberg, E. Influence of biocorona formation on the transformation and dissolution of cobalt nanoparticles under physiological conditions. ACS Omega 2019, 4, 21778-21791. [CrossRef]

22. Doane, T.L.; Chuang, C.-H.; Hill, R.J.; Burda, C. Nanoparticle ל-potentials. Acc. Chem. Res. 2012, 45, 317-326. [CrossRef]

23. Pradhan, S.; Hedberg, J.; Blomberg, E.; Wold, S.; Odnevall Wallinder, I. Effect of sonication on particle dispersion, administered dose and metal release of non-functionalized, non-inert metal nanoparticles. J. Nanopart. Res. 2016, 18, 285. [CrossRef]

24. Navarro, E.; Baun, A.; Behra, R.; Hartmann, N.B.; Filser, J.; Miao, A.-J.; Quigg, A.; Santschi, P.H.; Sigg, L. Environmental behavior and ecotoxicity of engineered nanoparticles to algae, plants, and fungi. Ecotoxicology 2008, 17, 372-386. [CrossRef]

25. Zhou, K.; Hu, Y.; Zhang, L.; Yang, K.; Lin, D. The role of exopolymeric substances in the bioaccumulation and toxicity of Ag nanoparticles to algae. Sci. Rep. 2016, 6, 32998. [CrossRef] [PubMed]

26. Su, C.; Suarez, D.L. In situ infrared speciation of adsorbed carbonate on aluminum and iron oxides. Clays Clay Miner. 1997, 45 , 814-825. [CrossRef]

27. Nakamoto, K. Infrared and Raman Spectra of Inorganic and Coordination Compounds. In Handbook of Vibrational Spectroscopy; Chalmers, J.M., Griffiths, P.R., Eds.; John Wiley \& Sons, Ltd.: Hoboken, NJ, USA, 2006.

28. Pradhan, S.; Hedberg, J.; Rosenqvist, J.; Jonsson, C.M.; Wold, S.; Blomberg, E.; Odnevall Wallinder, I. Influence of humic acid and dihydroxy benzoic acid on the agglomeration, adsorption, sedimentation and dissolution of copper, manganese, aluminum and silica nanoparticles-A tentative exposure scenario. PLoS ONE 2018, 13, e0192553. [CrossRef] [PubMed]

29. Kačuráková, M.; Capek, P.; Sasinková, V.; Wellner, N.; Ebringerová, A. FT-IR study of plant cell wall model compounds: Pectic polysaccharides and hemicelluloses. Carbohydr. Polym. 2000, 43, 195-203. [CrossRef]

30. Barth, A. The infrared absorption of amino acid side chains. Prog. Biophys. Mol. Biol. 2000, 74, 141-173. [CrossRef] 
31. Nasser, F.; Lynch, I. Secreted protein eco-corona mediates uptake and impacts of polystyrene nanoparticles on Daphnia magna. J. Proteom. 2016, 137, 45-51. [CrossRef]

32. Hay, M.B.; Myneni, S.C.B. Structural environments of carboxyl groups in natural organic molecules from terrestrial systems. Part 1: Infrared spectroscopy. Geochim. Cosmochim. Acta 2007, 71, 3518-3532. [CrossRef]

33. Barth, A.; Zscherp, C. What vibrations tell about proteins. Q. Rev. Biophys. 2002, 35, 369-430. [CrossRef] [PubMed]

34. Wu, H.; Gonzalez-Pech, N.I.; Grassian, V.H. Displacement reactions between environmentally and biologically relevant ligands on $\mathrm{TiO}_{2}$ nanoparticles: Insights into the aging of nanoparticles in the environment. Environ. Sci. Nano 2019, 6, 489-504. [CrossRef]

35. Mudunkotuwa, I.A.; Minshid, A.A.; Grassian, V.H. ATR-FTIR spectroscopy as a tool to probe surface adsorption on nanoparticles at the liquid-solid interface in environmentally and biologically relevant media. Analyst 2014, 139, 870-881. [CrossRef]

36. Quigg, A.; Chin, W.-C.; Chen, C.-S.; Zhang, S.; Jiang, Y.; Miao, A.-J.; Schwehr, K.A.; Xu, C.; Santschi, P.H. Direct and indirect toxic effects of engineered nanoparticles on algae: role of natural organic matter. ACS Sustain. Chem. Eng. 2013, 1, 686-702. [CrossRef]

37. Hedberg, J.; Blomberg, E.; Odnevall Wallinder, I. In the search for nanospecific effects of dissolution of metallic nanoparticles at freshwater-like conditions: a critical review. Environ. Sci. Technol. 2019, 53, 4030-4044. [CrossRef] [PubMed]

38. Lead, J.R.; Batley, G.E.; Alvarez, P.J.J.; Croteau, M.-N.; Handy, R.D.; McLaughlin, M.J.; Judy, J.D.; Schirmer, K. Nanomaterials in the environment: Behavior, fate, bioavailability, and effects-An updated review. Environ. Toxicol. Chem. 2018, 37, 2029-2063. [CrossRef]

39. Misra, S.K.; Dybowska, A.; Berhanu, D.; Luoma, S.N.; Valsami-Jones, E. The complexity of nanoparticle dissolution and its importance in nanotoxicological studies. Sci. Total Environ. 2012, 438, 225-232. [CrossRef]

40. Zhao, J.; Cao, X.; Liu, X.; Wang, Z.; Zhang, C.; White, J.C.; Xing, B. Interactions of CuO nanoparticles with the algae Chlorella pyrenoidosa: Adhesion, uptake, and toxicity. Nanotoxicology 2016, 10, 1297-1305. [CrossRef]

41. Ma, S.; Zhou, K.; Yang, K.; Lin, D. Heteroagglomeration of oxide nanoparticles with algal cells: effects of particle type, ionic strength and pH. Environ. Sci. Technol. 2015, 49, 932-939. [CrossRef]

42. Yue, Y.; Li, X.; Sigg, L.; Suter, M.J.F.; Pillai, S.; Behra, R.; Schirmer, K. Interaction of silver nanoparticles with algae and fish cells: A side by side comparison. J. Nanobiotechnol. 2017, 15, 16. [CrossRef] [PubMed]

43. Nasser, F; Lynch, I. Updating traditional regulatory tests for use with novel materials: Nanomaterial toxicity testing with Daphnia magna. Saf. Sci. 2019, 118, 497-504. [CrossRef]

44. Hedberg, J.; Ekvall, M.T.; Hansson, L.-A.; Cedervall, T.; Odnevall Wallinder, I. Tungsten carbide nanoparticles in simulated surface water with natural organic matter: Dissolution, agglomeration, sedimentation and interaction with Daphnia magna. Environ. Sci. Nano 2017, 4, 886-894. [CrossRef]

45. van den Brink, N.W.; Jemec Kokalj, A.; Silva, P.V.; Lahive, E.; Norrfors, K.; Baccaro, M.; Khodaparast, Z.; Loureiro, S.; Drobne, D.; Cornelis, G.; et al. Tools and rules for modelling uptake and bioaccumulation of nanomaterials in invertebrate organisms. Environ. Sci. Nano 2019, 6, 1985-2001. [CrossRef]

46. Davis, A.; Nasser, F.; Lead, J.R.; Shi, Z. Development and application of a ratiometric nanosensor for measuring $\mathrm{pH}$ inside the gastrointestinal tract of zooplankton. Environ. Sci. Nano 2020, 7, 1652-1660. [CrossRef]

47. Blust, R. 6-Cobalt. In Fish Physiology; Wood, C.M., Farrell, A.P., Brauner, C.J., Eds.; Academic Press: Waltham, MA, USA, 2011; Volume 31, pp. 291-326.

48. Zhang, Z.; Tian, X.; Li, D. Tissue $\mathrm{pH}$ and gut ecomorphology in six freshwater teleosts occupying different trophic levels. Turk. J. Zool. 2016, 40, 713-719. [CrossRef]

49. Miller, J.; Miller, J.C. Statistics and Chemometrics for Analytical Chemistry, 4th ed.; Pearson Education Limited: Harlow, UK, 2000. 